\title{
A Theory of Entry into and Exit from Export Markets*
}

\author{
Giammario Impullitti; $\quad$ Alfonso A. Irarrazabal; \\ Cambridge University Norges Bank
}

\author{
Luca David Opromolla ${ }^{\S}$ \\ Banco de Portugal \& UECE
}

September 11, 2012

\begin{abstract}
This paper introduces idiosyncratic firm efficiency shocks into a continuous-time general equilibrium model of trade with heterogeneous firms. The presence of sunk export entry costs and efficiency uncertainty gives rise to hysteresis in export market participation. A firm will enter into the export market once it achieves a given size, reflecting its efficiency, but may keep exporting even after its efficiency has fallen below its initial entry level. Some exporters will not be selling as much in the domestic market as other firms that never entered the foreign market. The model captures the qualitative features of firm birth, growth, export market entry and exit, and death found in the empirical literature. We calibrate the model to match relevant statistics of firms' turnover and export dynamics in the United States, and show that the mode of globalization (a reduction in sunk costs as opposed to overhead costs), matters for a firm's selection and persistence in export status. Trade liberalization via a reduction in sunk export entry costs reduces a firm's export status persistence, while the opposite happens when liberalization takes place through a reduction in overhead export costs.
\end{abstract}

JEL Codes: F10, L11

Keywords: Export, Hysteresis, Brownian Motion, Sunk Costs

*We would like to express our gratitude to Jonathan Eaton for his advice and constant support. We greatly benefited from the comments and suggestions of two anonymous referees and from discussions with João Amador, Pol Antràs, Gian Luca Clementi, and Costas Arkolakis. We are especially gratefull to Atilla Yilmaz who helped us dealing with stochastic processes. A previous version of this paper circulated under the title "Hysteresis in Export Markets". Luca David Opromolla acknowledges financial support from Portuguese national funds by FCT (Fundação para a Ciência e a Tecnologia). This article is part of the Strategic Project: PEst-OE/EGE/UI0436/2011. The analysis, opinions and findings represent the views of the authors, they are not necessarily those of the Banco de Portugal or Norges Bank.

${ }^{\dagger}$ Faculty of Economics, Cambridge University, gi218@cam.ac.uk

$\ddagger$ Research Department, Norges Bank: Alfonso.Irarrazabal@norges-bank.no.

$\S$ Departamento de Estudos Economicos, Banco de Portugal and UECE - Research Unit on Complexity and Economics of ISEG, School of Economics and Management of the Technical University of Lisbon: ldopromolla@bportugal.pt. 


\section{Introduction}

In recent years many studies have highlighted the importance of producer heterogeneity in international trade. On average, the most productive firms are those that engage in exporting activities, a finding that suggests substantial hurdles exist in accessing the foreign market. ${ }^{1}$ Moreover, firms perform very differently after entering the export market: while a large fraction of new exporters stop exporting within a year of their entry, those new exporters that survive are very likely to thrive ${ }^{2}$ Heterogeneity in export performance also reveals itself through the fact that cohorts of exporters differ in their performance over the years, with leapfrogging in size and productivity occurring.

Despite this heterogeneity, a firm's trade status is very persistent. Roberts and Tybout (1997), using data on Colombian plants, found that sunk entry costs are significant and a firm's prior experience increases its probability of exporting by as much as 60 percentage points. Bernard and Jensen (2004a), using data for U.S. plants, Campa (2004) using data on Spanish firms, and Bernard and Wagner (2001) using data on German firms, all find a large degree of persistence in a firm's export status ${ }^{3}$ Moreover, Bernard and Jensen (2004b) show that U.S. firms start and stop exporting at different productivity levels, with exporters exiting at a productivity level one-third below the productivity level at which they start exporting. Finally, Bernard et al. (2003) show that although the productivity distribution of U.S. exporters stochastically dominates that of nonexporters, the two distributions overlap for a large part of the productivity support, thus suggesting the presence of low-productivity exporters and highproductivity nonexporting firms.

This paper provides a new model which rationalizes the above facts. Our framework is similar to Melitz (2003) but instead of assuming that a firm's efficiency remains constant over time, we suppose that it evolves over the life of the firm as a consequence of the realization of a Brownian motion stochastic process. In order to enter a foreign market firms need to pay a sunk entry cost. Due to the presence of sunk costs and uncertainty, the decision to start or stop exporting can be analyzed following the literature on investment under uncertainty (e.g. Dixit 1989, Dixit and Pindyck 1994). Entrepreneurs make investments to set up firms and draw their initial efficiency level from a common distribution. Thereafter, efficiency evolves over time according to a Brownian motion. Production for the domestic market starts even if

\footnotetext{
${ }^{1}$ Among many see, for instance, Bernard and Jensen (1995).

${ }^{2}$ Eaton et al. (2008) provided a thorough analysis of firm-specific export patterns using Colombian data for the period 1996-2005. Amador and Opromolla (2013) found similar results using Portuguese data for the same time period.

${ }^{3}$ Bernard and Jensen (2004a) found that 85 percent of the plants that exported in 1984 are still exporting in 1985. Moreover, 89 percent of the plants that were not exporting in 1984 still did not export in 1985. Campa (2004) found that between 1990 and 1997 about 90 percent of the firms that were not exporting in a year keep not exporting in the following year. For exporters the percentage of firms that do not switch status is around 95 percent. Bernard and Wagner (2001) found that the percentage of firms that do not switch export status from one year to the next is 94 for exporters and 95 percent for nonexporters in the 1979-1992 period.
} 
profits are negative and continues until the expected net present value of profits and the value of the option to start exporting are high enough. If the firm's efficiency exceeds an endogenously determined threshold, it then becomes profitable to enter the foreign market by paying a sunk cost. This entry cost has to be paid every time a firm starts or resumes exporting. If, later on, efficiency falls below the initial level at which the firm had started exporting, the entrepreneur will prefer to keep exporting as long as the net present value of exporting profits plus the value of the option to stop exporting is larger than the value of being a nonexporter. In other words, the presence of uncertainty and sunk export entry costs introduces an option value in the decision to enter or exit the export market. Current exporters wait longer to leave the export market in order to avoid repaying the entry cost later on, though this choice comes at the expense of enduring periods of negative (export) profits. Similarly, nonexporters wait for higher efficiency levels before entering the export market. Overall, export participation is characterized by hysteresis $4^{4}$ There is a range of efficiency levels where the optimal decision is to stick with the status quo: nonexporters decide not to enter the export market and exporters decide not to leave it. In the irreversibility literature (e.g. Dixit 1989, Dixit and Pyndick 1994) this is known as the band of inaction.

We extend Dixit's 1989 model, which considers the decision of entry and exit from an industry when prices are stochastic. In our model we consider the export market entry and exit decision in a general equilibrium framework with heterogeneous firms. Uncertainty and the sunk costs of exporting are also present in Roberts and Tybout (1997). They developed a dynamic discrete-choice model that expresses each plant's current exporting status as a function of its previous exporting experience, its observable characteristics affecting future profits from exporting, and unobserved serially correlated shocks. More recently, Das et al. (2007) develop and estimate a partial equilibrium dynamic structural model of export supply with plant-level heterogeneity in export profits, market entry costs and uncertainty. All in all, our model, maintaining these same three elements, embeds these models into a fully-fledged general-equilibrium framework.

Our paper is related to Luttmer (2007). We extend his industry dynamics framework to allow firms to compete in the international market and we retain his prediction that the firm size distribution is Pareto in the upper tail and increasing in the lower tail. In addition, our model also implies that the distribution of exporters' sales into a foreign market is Pareto in the upper tail and increasing in the lower tail. This result is consistent with recent evidence by Eaton et al. (2011). Using data from France they report that export sales distributions behave similarly to a Pareto distribution in the upper tail and more like a lognormal distribution in the lower tail, independent of market size and the extent of French participation. Export sales

\footnotetext{
${ }^{4}$ The idea of hysteresis was first put forward by Baldwin (1990). Baldwin and Krugman (1989) further formalize the idea that the exchange rate can have persistent effects on international trade. Antràs (2004) discusses how the coupling of sunk costs and uncertainty gives rise to hysteresis in the export market.
} 
distributions are therefore similar to the overall firm size distribution (e.g. Axtell 2001, Luttmer 2007). Unlike in Luttmer's 2007 model, the case of two (or more) trading economies requires decomposing the stationary efficiency distribution in two parts: one for exporters and the other one for nonexporters. When the underlying uncertainty follows a standard Brownian motion the efficiency distributions of exporters and nonexporters overlap along the band of inaction: the most efficient nonexporters lie to the right of (i.e. are more efficient than) the least efficient exporters.

Our paper is also related to Arkolakis (2010), where the author introduces per consumer access costs to explain the presence of "small" exporters. In Melitz (2003), less efficient firms can enter the foreign market and sell small amounts only if the export overhead cost is small relatively to the size of the destination market. In our model, the presence of an export sunk cost (on top of the overhead cost) makes it more difficult for incumbent exporters to leave the foreign market. Therefore, we offer a different but complementary rationale for the existence of small exporters even when their overhead costs are high. These are exporters that entered the export market and experienced larger initial export sales, but then suffered a sequence of negative efficiency shocks that reduced sales - but not to the point of triggering exit from the export market. This pattern is due to the hysteresis effect and is consistent with the evidence, mentioned above, provided in Bernard and Jensen (2004b), as well as with Eaton et al. (2008), who find that on a year-to-year basis a substantial fraction of Colombian exporters switch to lower export quintiles, without stopping to export.

Finally, other papers have introduced dynamics into a model of trade with heterogeneous firms. Ghironi and Melitz (2005) incorporated heterogeneous firms into a two country dynamic stochastic general equilibrium model to study the effects of aggregate shocks on the size of the traded sector and the composition of consumption baskets in both countries. Aggregate shocks induce firms to enter and exit, which results in changes to the composition of the consumption basket over time. In contrast to our model, fixed costs occur per period and, therefore, there is no band of inaction. Closer to our model Alessandria and Choi (2012) develop a general equilibrium model with heterogeneous firms, sunk export costs, and persistent idiosyncratic productivity shocks to assess the quantitative effects of a tariff reduction on welfare, trade, and export participation. By devising the model in discrete time they cannot provide closed-form solutions for the stationary size distribution of exporters and nonexporters. Costantini and Melitz (2008), Atkeson and Burstein (2010), and Impullitti and Licandro (2010) focus on the firm's joint decision to export and innovate, thus endogenizing the dynamics of productivity.

In the second part of the paper we calibrate the model to match relevant statistics of firms' turnover and export dynamics for the U.S. economy, and explore its properties numerically. First, this exercise allows us to provide an estimate of the sunk and overhead costs of exporting, which turn out to be in line with those estimated by Das et al. (2007) using Colombian data. Second, the calibration allows us to quantify the band of inaction, and study how it is affected 
by different globalization scenarios. We focus on the reduction in two different types of fixed trade costs, the sunk export entry cost and the overhead (per-period, on-going) export cost, and discuss the implications of these different modes of globalization for firms' selection into the export market, the persistence in export status, and the new exporters' margin of trade liberalization.

The paper is structured as follows. Section 2 presents the basic set-up, solves for the stationary efficiency distributions by export status, and describes the equilibrium. Section 3 performs a quantitative analysis, based on U.S. data, of the model and focuses on a firm's persistence in export status. Finally, section 4 concludes.

\section{Model}

\subsection{Basic Set-up}

In this section we introduce the basic features of the model. We define preferences, technology, trade costs, market structure, and we determine the optimal pricing behavior.

Demand. Time is continuous and starts at $t=0$. There are two symmetric countries, each populated by a measure $L$ of infinitely lived agents. Consumers in each country maximize utility derived from the consumption of goods from one sector, characterized by a continuum of differentiated goods. Utility comes from the consumption of a composite good $C$ and is equal to

$$
\int_{0}^{\infty} e^{-\rho t} \ln C_{t} d t
$$

where $\rho>0$ is the discount rate.$^{5}$ The composite good is a CES aggregator of the set $\Omega_{c}$ of differentiated varieties $c$ available in equilibrium:

$$
C=\left(\int_{\Omega_{c}} c^{\frac{\sigma-1}{\sigma}} d c\right)^{\frac{\sigma}{\sigma-1}}
$$

where $\sigma>1$ is the elasticity of substitution between any two varieties. When the composite good is used as the numéraire, the interest rate is constant and given by $r=\rho$. Aggregate consumption (and wages) do not grow in the steady state. A positive interest rate ensures that the present value of aggregate expenditure and aggregate labor income is finite and that utility is finite.

Since varieties symmetrically enter the utility function, demand for a variety depends (only) on its price $p$,

$$
c(p)=C p^{-\sigma} .
$$

\footnotetext{
${ }^{5}$ Since we focus on the analysis of the steady state and we do not introduce aggregate growth in the model, we now drop the time subscript whenever possible in order to simplify the notation.
} 
Each consumer is endowed, at every point in time, with one unit of labor which is supplied inelastically to firms and receives a wage $w$. The representative consumer faces a standard present value budget constraint.

Technology, trade barriers, and optimal pricing. Creating a firm requires an initial investment in the form of a sunk cost $\lambda_{E}$, expressed in units of labor. Goods are produced using only labor. A firm is defined by its unique access to a technology for producing a particular differentiated commodity. Firm technology is represented by a cost function that exhibits a constant marginal cost with a fixed overhead cost. At age $a$, a firm uses $l_{a}=c / e^{z_{a}}+\lambda_{0}$ units of labor to produce $c$ units of a differentiated good. The (labor) efficiency level of the firm at age $a$ is denoted by $z_{a}$. An existing firm can only continue at a cost equal to $\lambda_{0}$ units of labor per unit of time. The firm must exit if this flow cost is not paid, and any exit is irreversible. After sustaining the entry cost $\lambda_{E}$, the firm draws an initial random unit log labor efficiency from a distribution $g(z)$. For pure expositional purposes, we present the model under the assumption that all new firms enter with the same efficiency level, denoted with $\bar{z}$.

Firms can sell their product only on the domestic market or also export it. An exporter faces three types of trade barriers: a variable cost $\tau$, a per period cost $\lambda_{1}$, and an up-front cost I. The variable cost takes the form of an "iceberg cost": $\tau>1$ units of the good must be shipped in order for one unit of the good to arrive in the other country. The additional cost $\lambda_{1}$ has to be paid every period by an exporting firm. Think of $\lambda_{1}$ as the cost of maintaining a presence in the foreign market, including minimum freight and insurance charges, and the costs of monitoring foreign customs procedures and product standards. The cost $I$ has to be sunk up-front every time a firm starts or resumes exporting. It represents expenses like the cost of establishing distribution channels, learning bureaucratic procedures, developing a marketing strategy, and adapting products and packaging for the foreign market. Both the per period cost and the up-front cost are expressed in units of labor. Unlike in Melitz (2003), these two trade costs play different roles in our model, as it will become clear below.

Firms operate in monopolistically competitive markets, and apply a standard Dixit-Stiglitz markup on marginal costs. The optimal domestic price of a firm with efficiency $z_{a}$ is

$$
p\left(z_{a}\right)=\frac{\sigma}{\sigma-1} \frac{w}{e^{z_{a}}}
$$

while the export price is equal to the domestic price multiplied by a factor $\tau$. Let $j$ denote the status of a firm ( 0 for a nonexporter; 1 for an exporter). The flow profits (i.e. gross of fixed costs) of a nonexporter are

$$
\tilde{\pi}_{0}\left(z_{a}\right)=\frac{1}{\sigma}\left(\frac{\sigma-1}{\sigma}\right)^{\sigma-1} X w e^{(\sigma-1) z_{a}},
$$


where $X=w^{(1-\sigma)} C / w$, can be interpreted as a proxy for market size. The flow profits of an exporter with efficiency $z_{a}$ are $\tilde{\pi}_{1}\left(z_{a}\right)=\left(1+\tau^{1-\sigma}\right) \tilde{\pi}_{0}\left(z_{a}\right)$. It will be convenient, below, to re-express the flow profits as relative to the value of domestic fixed costs, i.e.

$$
\pi_{0}\left(z_{a}\right)=\frac{\tilde{\pi}_{0}\left(z_{a}\right)}{w \lambda_{0}}
$$

for a nonexporter and $\pi_{1}\left(z_{a}\right)=\tilde{\pi}_{1}\left(z_{a}\right) /\left(w \lambda_{0}\right)$ for an exporter, respectively.

\subsection{The Entry and Exit Problem of the Firm}

In Melitz (2003) firms' efficiencies do not vary over time, implying that operating profits are also constant through time and therefore a firm either never exports or always exports. In this paper we depart from this outcome and, following Luttmer (2007), we assume that efficiencies evolve, independently across firms, according to

$$
z_{a}=\bar{z} \exp \left(\mu a+\xi W_{a}\right)
$$

where $\left\{W_{a}\right\}_{a \geq 0}$ is a standard Brownian motion, $\mu \in \mathbb{R}$ is a trend of log efficiency, and $\xi \geq 0$ is the variance parameter. Changes in efficiency (over the age of a firm) can be interpreted as permanent idiosyncratic shocks to technology (i.e. producing the same variety at a lower cost) or to quality (i.e. producing a better variety at the same cost). As a result of these shocks, the firm's optimal price, labor demand, revenues, profits, and export participation evolve stochastically over time. All nonexporters have a chance of becoming exporters and some firms do actually export. The performance of a new exporter depends on the particular realization of the efficiency sample path according to equation (2).

The decision to start exporting or to stop exporting can be analyzed following the literature on investment under uncertainty (e.g. Dixit 1989, Dixit and Pindyck 1994). The decision to enter the foreign market presents two distinctive characteristics: first, it is a decision that is (partly) irreversible, in the sense that it entails sunk costs that cannot be (fully) recovered. Second, it is an investment that can be delayed, so that the firm has the opportunity to wait for new information to arrive about its potential profits before commiting resources. As such, we consider a firm that is currently serving only the domestic market as a composite asset, part of which is the option to start exporting (i.e. making the investment). If that option is exercised, the firm turns into a different asset, part of which is the option to stop exporting (i.e. abandon the investment). Given this circularity, the value of a nonexporter and of an exporter are interlinked, and must be determined simultaneously.

There are two state variables: the firm efficiency $z$ and its current export participation status $j$, where $j=0$ denotes a nonexporter while $j=1$ denotes an exporting firm. The overall state of the firm $(j, z)$ affects the instantaneous flow of profits (as shown above) and the value of 
the option to switch trade status. The decision problem of the firm is to switch optimally from nonexporting to exporting (and vice versa). The resulting value functions are $\tilde{V}_{0}(z)$ and $\tilde{V}_{1}(z)$, respectively. A nonexporting firm with efficiency $z$ has value $\tilde{V}_{0}(z)$. If the firm decides to start exporting its value becomes $\tilde{V}_{1}(z)$. As mentioned above, this requires sustaining a sunk cost. The value function in each state, net of the cost of the switch, is the terminal payoff function for the other state.

Intuition suggests that a nonexporter will begin exporting when efficiency (and therefore expected export sales) is high enough, and an exporter will exit the foreign market when conditions become sufficiently adverse. Moreover, we expect a firm to shut down when its competitiveness is so low that it is not even worthwhile to keep an active participation in the domestic market. Therefore consider a policy to enter the foreign market at $z_{H}$, exit the foreign market at $z_{L}$, and shut down at $z_{D}$, where $z_{D}<z_{L}<z_{H}$. The presence of sunk costs of entry and re-entry into the export market, coupled with efficiency shocks, creates a wedge between the efficiency level at which firms decide to start exporting, $z_{H}$, and the efficiency level at which firms decide to stop exporting, $z_{L}$. In the range of efficiency levels between the thresholds $z_{L}$ and $z_{H}$, the optimal policy is to continue with the status quo, whether it be exporting or nonexporting. The interval $\left(z_{L}, z_{H}\right)$ is therefore a band of inaction that is endogenously determined in the model $\left[^{6}\right.$ Firm's efficiency is not a sufficient statistics to determine the export status of a firm: a firm's history has to be taken into account.

\section{[Figure 1 about here]}

As an illustration, Figure 1 shows the efficiency sample paths of two types of firms. Both types start as nonexporters with efficiency $\bar{z}$. A type 1-firm switches to export at age $a_{H}$ when efficiency passes the $z_{H}$ cutoff. After that point, we consider three possible types of realized efficiency paths. First, efficiency can be somewhat stable (or rise) and the firm keeps exporting (sub-type 1A). Second, efficiency can decline, even below the level at which the firm had started exporting, $z_{H}$, but not below $z_{L}$, so that the firm does not switch trade status (sub-type 1B). Third, efficiency can decline below $z_{L}$, and the firm exits the export market (sub-type 1C). Eaton et al. (2008), using firm-level data for Colombia, find that "The heterogeneity in export growth conditional on survival suggests that, among firms attaining the threshold profitability of operating in a new destination, there is a wide variety in export performance thereafter." The second firm sub-type never starts to export (i.e. does not reach the $z_{H}$ cutoff). After an initial rise, efficiency declines (sub-type $2 \mathrm{~A}$ and $2 \mathrm{~B}$ ), possibly to the point where it is preferable to shut down the firm (sub-type $2 \mathrm{~B}$ ). It is important to note that between $z_{L}$ and $z_{H}$ there can be both exporters and nonexporters. To understand this status, the history of the firm has to be taken into account. In Figure 1, type 1 firms with efficiency $z^{*}$ do not export when their age is

\footnotetext{
${ }^{6}$ This intuition will be formalized and discussed more in detail below.
} 
below $a_{H}$, but do export (at the same efficiency level) when their path is that of sub-type $1 \mathrm{C}$. Type 2 firms never export when their efficiency is equal to $z^{*}$ (or above).

Before turning to a rigorous analysis of a firm's export entry and exit decisions, we make another assumption: each firm, at each point in time, can be hit by an exogenous shock and shut down with probability $\delta$. Therefore, in this model, there are two reasons why firms can exit: because of a negative efficiency shock or because of the killing rate $\delta$. Although there are some realistic examples of severe shocks that would constrain a firm to exit independently of efficiency (e.g. natural disasters, new regulation, product liability, major changes in consumers' tastes), it is also likely that exit may be caused by a series of bad shocks affecting the firm's efficiency.

The entry problen $!^{7}$ First, consider the problem of a nonexporter with efficiency $z$ deciding at age 0 whether to enter the export market at age $a \geq 0.8$ Let $V_{j}(z)=\tilde{V}_{j}(z) / w \lambda_{0}$ denote the value functions relative to the value of domestic fixed costs. $9^{9} V_{0}(z)$ is the current value of the firm. At the moment of entry $a$ the firm pays the sunk cost $I / \lambda_{0}$ and its value switches to $V_{1}\left(z_{a}\right)$. Therefore

$$
V_{0}(z)=\sup _{a \geq 0} E\left\{\int_{0}^{a}\left[\pi_{0}\left(z_{s}\right)-1\right] e^{-(\rho+\delta) s} d s+\left[V_{1}\left(z_{a}\right)-\frac{I}{\lambda_{0}}\right] e^{-(\rho+\delta) a}\right\},
$$

where the expectation operator is conditional on the initial given value $z$. The firm optimally chooses the entry moment $a$ as follows. If the firm enters straightaway it pays a sunk cost $I / \lambda_{0}$ and its value switches to $V_{1}(z)$. Alternatively, the firm could stay out of the market for an infinitesimal time, denoted by $d a$, when its efficiency has changed to $(z+d z)$. The payoff from this strategy is a cash flow equal to the value of current domestic profits $\left[\pi_{0}(z)-1\right] d a$ and the expected continuation value $E\left[V_{0}(z+d z)\right]$. By Itô's Lemma we have:

$$
E\left[V_{0}(z+d z)\right]=V_{0}(z)+\left[\mu V_{0}^{\prime}(z)+\frac{1}{2} \xi^{2} V_{0}^{\prime \prime}(z)\right] d a
$$

where derivatives of the value functions are taken with respect to $z$. By Bellman's Principle of Optimality, $V_{0}(z)$ must be the best alternative, that is,

$$
V_{0}(z)=\max \left\{V_{1}(z)-\frac{I}{\lambda_{0}},\left[\pi_{0}(z)-1\right] d a+V_{0}(z)+\left[\mu V_{0}^{\prime}(z)+\frac{1}{2} \xi^{2} V_{0}^{\prime \prime}(z)-(\rho+\delta) V_{0}(z)\right] d a\right\}
$$

\footnotetext{
${ }^{7}$ The problem of the firm that we are about to analyze is also called "an optimal stopping time" problem. The reader might find it useful to compare the equilibrium conditions derived below with Figure 2 in section 3 , where we use the calibrated parameters to plot the value functions $V_{0}$ and $V_{1}$, as well as their difference.

${ }^{8}$ For simplicity we chose to consider the problem of a firm at age 0 . Of course, the following applies at any age of the firm.

${ }^{9}$ We express the value functions in terms of the domestic fixed costs in order to facilitate the comparison with Luttmer (2007).
} 
This gives the following conditions.

1. At all $z$ where it is optimal to stay as a nonexporter, i.e. $\forall z \in\left(z_{D}, z_{H}\right)$, two conditions apply. First, we have the Bellman equation,

$$
(\rho+\delta) V_{0}(z)=\pi_{0}(z)-1+\mu V_{0}^{\prime}(z)+\frac{1}{2} \xi^{2} V_{0}^{\prime \prime}(z) .
$$

The Bellman equation (4) makes it clear that the entitlement to the flow of domestic profits is an asset, and that $V_{0}(z)$ is its value. On the equation's left-hand side we have the normal return per unit of time that a decision maker (i.e. the firm's owner), using $(\rho+\delta)$ as the discount rate, would require for holding this asset. On the right-hand side, the first term is the immediate payout or dividend from the asset, while the second term is its expected rate of capital gain (or loss). Thus the right-hand side is the expected total return per unit time from holding the asset. The equality becomes a no-arbitrage or equilibrium condition, expressing the investor's willingness to hold the asset, i.e. the willingness to stay as a nonexporter. The second condition is the inequality,

$$
V_{0}(z) \geq V_{1}(z)-\frac{I}{\lambda_{0}},
$$

which implies that the second term in the max function (3) is bigger than the first one.

2. Similarly, at all $z$ where switching to exporting is optimal, i.e. $\forall z \in\left(z_{H}, \infty\right)$, we have two conditions. First, the inequality,

$$
(\rho+\delta) V_{0}(z) \geq \pi_{0}(z)-1+\mu V_{0}^{\prime}(z)+\frac{1}{2} \xi^{2} V_{0}^{\prime \prime}(z),
$$

which shows that, using again the no-arbitrage interpretation introduced above, the normal return per unit of time required for holding the "non-exporting" asset is higher than its expected total return. Therefore, an investor would prefer not to hold the asset anymore, i.e. to pay the cost $I / \lambda_{0}$, exercise the option right, and receive in return a new asset (i.e. "being an exporter") whose value is $V_{1}(z)$. The second condition (often called "the value-matching condition") implies that, over the range $\left(z_{H}, \infty\right)$, the first term in the max function in (3) is the bigger one,

$$
V_{0}(z)=V_{1}(z)-\frac{I}{\lambda_{0}} .
$$

Moreover, it can be shown that optimality requires that, at the threshold $z_{H}$, the values $V_{0}(z)$ and $V_{1}(z)-I / \lambda_{0}$, regarded as a function of $z$, should meet tangentially. In other words, 
the following "smooth pasting" condition must hold 10 ,

$$
V_{0}^{\prime}\left(z_{H}\right)=V_{1}^{\prime}\left(z_{H}\right)
$$

We also assume that the scrap value of a firm is zero, which implies that the value of a nonexporter is zero for efficiency levels below the industry exit cutoff, i.e.

$$
V_{0}(z)=0
$$

for $z \in\left(-\infty, z_{D}\right)$. Again, for reasons similar to those mentioned above, optimality also requires the following smooth pasting condition:

$$
V_{0}^{\prime}\left(z_{D}\right)=0
$$

The exit problem. Now consider the problem of an exporter with efficiency $z$ deciding at age 0 whether to exit the export market at age $a \geq 0$. The firm receives profits from domestic and export sales for instants $s<a$, and the value $V_{0}\left(z_{a}\right)$ at $a$. Therefore,

$$
V_{1}(z)=\sup _{a \geq 0} E\left\{\int_{0}^{a}\left[\pi_{1}(z)-\frac{\lambda_{0}+\lambda_{1}}{\lambda_{0}}\right] e^{-(\rho+\delta) s} d s+V_{0}\left(z_{a}\right) e^{-(\rho+\delta) a}\right\} .
$$

The value of an exporter, with current efficiency $z$, is $V_{1}(z)$. The firm must compare the payoff from exiting immediately with the return from continuing to export for an infinitesimal time, $d a$. Calculations similar to those above yield the following conditions:

1. At all $z$ where it is optimal to keep exporting, i.e. $\forall z \in\left(z_{L}, \infty\right)$, we have the following Bellman equation,

$$
(\rho+\delta) V_{1}(z)=\pi_{1}(z)-\frac{\lambda_{0}+\lambda_{1}}{\lambda_{0}}+\mu V_{1}^{\prime}(z)+\frac{1}{2} \xi^{2} V_{1}^{\prime \prime}(z)
$$

\footnotetext{
${ }^{10}$ The smooth pasting condition is a requirement for optimality. Dixit (1989) and Dixit and Pindyck (1994), respectively, provide an intuitive and more rigorous treatment of this type of conditions. The intuition is that if the smooth pasting condition did not hold the value functions would meet at a kink. It can be proved that, both in the case of an upward kink and in the case of a downward kink, the optimal entry/exit strategy of the firm would contradict the one described. For example, if $V_{0}($.$) and V_{1}()-.I / \lambda_{0}$ were to meet at a downward kink in $z_{H}$, then $z_{H}$ could not be a point of indifference between continuing (as a nonexporter) and switching to export. To see that, consider a point $z^{*}=z_{H}(1+d t)$ to the right of $z_{H}$, and starting at $z^{*}$, consider the policy of remaining idle (i.e. do not start exporting) for time $d t$. During this time, the firm's productivity will spread out with a standard deviation of $\xi \sqrt{d t}$, which for small $d t$ is much larger than $d t$. The distribution of $(z+d z)$ spreads out across the kink. Then the convexity introduced by the kink makes $E V_{0}\left(z^{*}+d z\right) \exp [-(\rho+\delta) d t]$ significantly larger than $V_{0}\left(z^{*}\right)$. Since switching to export was supposed to be optimal to the right of $z_{H}$, such an improvement of value cannot occur, and therefore the kink cannot exist. If instead $V_{0}($.$) and V_{1}()-.I / \lambda_{0}$ were to meet at an upward kink in $z_{H}$ then, by continuity, $V_{0}($.$) would slightly exceed V_{1}()-.I / \lambda_{0}$ for $z$ slightly greater than $z_{H}$, and non-exporting would be optimal for such $z$, contrary to the definition of $z_{H}$ as the threshold.
} 
and the inequality condition

$$
V_{1}(z) \geq V_{0}(z)
$$

2. At all $z$ where it is optimal to exit, i.e. $\forall z \in\left(-\infty, z_{L}\right)$, we have the inequality condition,

$$
(\rho+\delta) V_{1}(z) \geq \pi_{1}(z)-\frac{\lambda_{0}+\lambda_{1}}{\lambda_{0}}+\mu V_{1}^{\prime}(z)+\frac{1}{2} \xi^{2} V_{1}^{\prime \prime}(z)
$$

and the value-matching condition,

$$
V_{1}(z)=V_{0}(z)
$$

Finally, the following smooth pasting condition applies, thus

$$
V_{1}^{\prime}\left(z_{L}\right)=V_{0}^{\prime}\left(z_{L}\right)
$$

The value function $V_{1}(z)$ must also be close to the present value of $\left\{\pi_{1}\left(z_{a}\right)-\left(\lambda_{0}+\lambda_{1}\right) / \lambda_{0}\right\}_{a \geq 0}$ when $z_{0}=z$ is large: when an exporter is extremely efficient the option to stop exporting becomes much less valuable and the value of the firm must then approach the present values of committing to sell both in the domestic and the foreign market forever.

The final condition that we need in order to be able to solve for the three efficiency cutoffs comes from assuming free entry. We assume that $M_{E}$ is the measure of new firms attempting to enter into the economy per unit of time. Successful entrants (with initial efficiency $\bar{z}$ larger than $z_{D}$ ) can start as exporters or as nonexporters. Since most new firms start very small we prefer to assume the latter, that is, $z_{D}<\bar{z}<z_{H}{ }^{11}$ Firms decide whether to enter the foreign market based on a comparison of the expected value of entry and the sunk entry cost. The free entry condition therefore takes the following form:

$$
\frac{\lambda_{E}}{\lambda_{0}}=V_{0}(\bar{z})
$$

The value functions $V_{0}(z), V_{1}(z)$, together with the three efficiency cutoffs $z_{D}, z_{L}$, and $z_{H}$, will be derived in Section (2.4). Before that, in the next Section, we close the model.

\footnotetext{
${ }^{11}$ The model can be easily specified and solved under the alternative condition $z_{D}<z_{H}<\bar{z}$. In general, the entrants' efficiency density $g(\bar{z})$ can be non-degenerate. We consider the "degenerate" case because it is easier to explain. Moreover, it requires a lower number of parameters and it's not a bad first approximation since most new firms are small.
} 


\subsection{Closing the model}

We close the model through labor market clearing. Labor supply is fixed to $L$. Labor is used for creating firms, $L_{E}$, sustaining the overhead costs, $L_{F}$, sustaining the variable production costs, $L_{P}$ and entering into the export market, $L_{I}$, according to

$$
\begin{gathered}
L_{E}=\lambda_{E} M_{E} \\
L_{F}=\left(\lambda_{0}+p \lambda_{1}\right) M_{E} \int_{z_{D}}^{\infty} f(z) d z \\
L_{P}=X\left(\frac{\sigma-1}{\sigma}\right)^{\sigma}\left[\int_{z_{D}}^{\infty} e^{(\sigma-1) z} f(z) d z+\tau^{-\sigma} \int_{z_{L}}^{\infty} e^{(\sigma-1) z} f_{1}(z) d z\right] M_{E}, \\
L_{I}=-I \frac{1}{2} \xi^{2} \frac{\partial f_{0}\left(z_{H}\right)}{\partial z} M_{E} .
\end{gathered}
$$

In equilibrium, there is a measure $M$ of active firms. These are described by a stationary efficiency density, $f(z)$, with nonzero support over $\left(z_{D}, \infty\right)$ and measure $M / M_{E}$. This density is equal to the sum of the efficiency density of the exporters, $f_{1}(z)$, with nonzero support over $\left(z_{L}, \infty\right)$ and measure $p M / M_{E}$, and the efficiency density of nonexporters, $f_{0}(z)$, with nonzero support over $\left(z_{D}, z_{H}\right)$ and measure $(1-p) M / M_{E}$, where $p$ denotes the (endogenous) fraction of exporters, $p$. Notice that, since we assume that the density $f(z)$ has measure $M / M_{E}$, it is not a probability density. The three efficiency densities, $f(z), f_{1}(z)$, and $f_{0}(z)$, and their corresponding probability densities, which we call $p(z), p_{1}(z)$, and $p_{0}(z)$, will be derived in Section (2.5), where we also derive the fraction of exporters $p .2^{12}$

Equation (17) above summarizes the total amount of labor used to create firms, equal to $\lambda_{E}$ multiplied by the measure of potential entrants, $M_{E}$. The second equation takes into account the amount of labor used to cover the domestic and export overhead costs. Recalling that the $f(z)$ density has measure $M / M_{E}$, it is easy to see that the $M_{E} \int_{z_{D}}^{\infty} f(z) d z$ term represents the measure $M$ of active firms. Therefore, the first term in equation (18) represents the total domestic overhead costs sustained by active firms, while the second term in (18) represents the additional overhead export costs paid by the fraction $p$ of exporting firms. The third equation covers labor used for the production of goods sold in the domestic and foreign market.13 The fourth equation summarizes the amount of labor used to cover the sunk entry cost of exporting by all those nonexporters that overcome the $z_{H}$ cutoff. This equality will become clear below. For now, it suffices to know that the set of firms that switch to exporting is related to the measure of non-exporting firms, as described by $f_{0}\left(z_{H}\right)$, that are close to the $z_{H}$ cutoff. ${ }^{14}$

Using the market-clearing condition, $L=L_{E}+L_{F}+L_{P}+L_{I}$, we can retrieve the measure

\footnotetext{
${ }^{12}$ We define the density $f(z)$ has having measure $M / M_{E}$ to facilitate the comparison with Luttmer (2007).

${ }^{13}$ It can be easily proved that the optimal demand for variable labor is $X[(\sigma-1) / \sigma]^{\sigma} \exp [(\sigma-1) z]$ for domestic production and an additional $\tau^{-\sigma} X[(\sigma-1) / \sigma]^{\sigma} \exp [(\sigma-1) z]$ for foreign sales.

${ }^{14}$ Recall that the measure of the density $f_{0}(z)$ is $M(1-p) / M_{E}$.
} 
of potential entrants $M_{E}$. Aggregate output is the sum of firm revenues (see the Appendix),

$$
\frac{Y}{w}=\left(\frac{\sigma-1}{\sigma}\right)^{\sigma-1} X\left[\int_{z_{D}}^{\infty} e^{(\sigma-1) z} f(z) d z+\left[1+\tau^{(1-\sigma)}\right] \int_{z_{L}}^{\infty} e^{(\sigma-1) z} f_{1}(z) d z\right] M_{E}
$$

In combination with the goods market clearing condition $C=Y$, this determines the ratio $C / w$. Given $X=w^{1-\sigma} C / w$, this pins down the wage $w$ and, using (21), $Y$.15 Finally, the measure of firms can be found using

$$
M=M_{E} \int_{z_{D}}^{\infty} f(z) d z
$$

In the next section we show how to solve for the value functions $V_{0}(z)$, and $V_{1}(z)$ together with $X$ and the equilibrium cutoffs $z_{D}, z_{L}$, and $z_{H}$. Given these cutoffs, in Section (2.5) we determine the equilibrium efficiency density, $f(z)$, the efficiency density of the exporters $f_{1}(z)$, and the efficiency density of nonexporters $f_{0}(z)$.

\section{$2.4 \quad$ Valuing the Options}

In this section we determine the equilibrium value functions $V_{0}(z)$ and $V_{1}(z)$, cutoffs $z_{D}, z_{L}$, and $z_{H}$, and $X$. The value functions $V_{0}(z)$ and $V_{1}(z)$ are general solutions to the differential equations (4) and (11). As such, the value functions can be constructed after finding particular solutions for (4) and (11), and general solutions for the corresponding homogeneous equations. The present values of committing to sell domestically forever, $W_{0}(z)$, and committing to sell in both markets forever, $W_{1}(z)$, are two particular solutions to equations (4) and (11):

$$
W_{0}(z)=\left[\pi_{0}(z)-1\right] r_{*}^{-1}, \quad W_{1}(z)=\left[\pi_{1}(z)-\frac{\lambda_{0}+\lambda_{1}}{\lambda_{0}}\right] r_{*}^{-1}
$$

where $r_{*}=\rho+\delta-\mu(\sigma-1)-1 / 2 \xi^{2}(\sigma-1)^{2}$ is a discount rate that takes into account the average growth rate of flow profits ${ }^{16}$ For $W_{0}(z)$ and $W_{1}(z)$ to be finite we need the following assumption,

\section{Assumption 1: $\quad r_{*}>0$.}

While $r>0$ ensures that the fixed cost of operating a firm forever is finite (recall that wages do not grow in the steady state), this assumption ensures that the revenues of such a policy are also finite. Overall the two assumptions guarantee that the value of a firm is finite.

\footnotetext{
${ }^{15}$ Specifically, $w=X^{1 /(1-\sigma)}(Y / w)^{1 /(\sigma-1)}$, and $Y=X^{1 /(1-\sigma)}(Y / w)^{\sigma /(\sigma-1)}$.

${ }^{16}$ Given the stochastic process for $z$ described in equation (2), it can be easily shown by applying Itô's Lemma that the flow of domestic profits follows a geometric Brownian motion with drift $\left[\mu(\sigma-1)+1 / 2 \xi^{2}(\sigma-1)^{2}\right] w \lambda_{0} \pi_{0}(z)$.
} 
The homogeneous equations corresponding to equations (4) and (11) take the form $(\rho+$

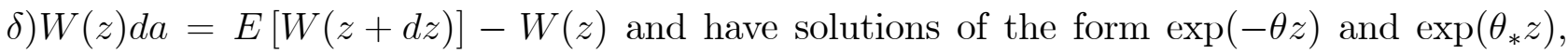
where $\theta$ and $\theta_{*}$ are positive constants,

$$
\left[\begin{array}{c}
\theta \\
\theta_{*}
\end{array}\right]=\left[\begin{array}{c}
\mu / \xi^{2}+\sqrt{\left(\mu / \xi^{2}\right)^{2}+(\rho+\delta) /\left(\xi^{2} / 2\right)} \\
-\mu / \xi^{2}+\sqrt{\left(\mu / \xi^{2}\right)^{2}+(\rho+\delta) /\left(\xi^{2} / 2\right)}
\end{array}\right] .
$$

Overall, the general solutions for $V_{0}(z)$ and $V_{1}(z)$ take the form,

$$
\begin{aligned}
& V_{0}(z)=W_{0}(z)+A_{0} e^{-\theta z}+B_{0} e^{\theta_{*} z}, \\
& V_{1}(z)=W_{1}(z)+A_{1} e^{-\theta z}+B_{1} e^{\theta_{*} z},
\end{aligned}
$$

for coefficients $\left(A_{j}, B_{j}\right)_{j=0,1}$ that remain to be determined. Note that the solutions of the homogeneous equations, incorporated in equations (23) and (24), include, respectively, the value of the option to start exporting and the value of the option to stop exporting. Since the option value to exit the export market is small for firms with large levels of efficiency, $V_{1}(z)$ has to be close to $W_{1}(z)$ for large values of $z$, and since $\theta_{*}$ is positive, it must be that $B_{1}=0$. The conditions (7), (9) and (14) then give rise to the boundary conditions,

$$
\begin{aligned}
V_{0}\left(z_{D} ; X, A_{0}, B_{0}\right) & =0 \\
V_{1}\left(z_{L} ; X, A_{1}\right) & =V_{0}\left(z_{L} ; X, A_{0}, B_{0}\right) \\
V_{0}\left(z_{H} ; X, A_{0}, B_{0}\right) & =V_{1}\left(z_{H} ; X, A_{1}\right)-\frac{I}{\lambda_{0}},
\end{aligned}
$$

where we have made explicit the dependence on all the unknown variables. The conditions above are often called the "value-matching conditions" because these match the values of the unknown functions $V_{0}($.$) , and V_{1}($.$) to those of the known termination payoff, as in the case$ of equation (25), or because these match the values of $V_{0}($.$) and V_{1}($.$) at some point on the$ common support, as in the case of conditions (26) and (27). These three boundary conditions are needed to solve for the remaining three coefficients $A_{0}, B_{0}$, and $A_{1}$, all of which are a function of $X, z_{D}, z_{L}$, and $z_{H}$. The equations are linear so this can be done analytically (see the Appendix). We need four more conditions to pin down $X, z_{D}, z_{L}$, and $z_{H}$. Three of these are the smooth pasting conditions (8), (10), and (15) computed at the boundary points $z_{D}, z_{L}$, and $z_{H}$. These three smooth pasting conditions require not just the values of $V_{0}(),. V_{1}($.$) , and$ the termination payoff, but also the derivatives of these functions, to match at the boundaries. The fourth condition comes from assuming free entry (see equation (16)). Overall, we need to 
solve the following system of equations:

$$
\begin{gathered}
V_{0}^{\prime}\left(z_{D} ; X, z_{L}, z_{H}\right)=0, \\
V_{1}^{\prime}\left(z_{L} ; X, z_{D}, z_{H}\right)=V_{0}^{\prime}\left(z_{L} ; X, z_{D}, z_{H}\right), \\
V_{0}^{\prime}\left(z_{H} ; X, z_{L}, z_{D}\right)=V_{1}^{\prime}\left(z_{H} ; X, z_{L}, z_{D}\right), \\
\lambda_{E}=\lambda_{0} V_{0}\left(\bar{z} ; X, z_{D}, z_{L}, z_{H}\right) \text { if } \bar{z} \in\left(z_{D}, z_{H}\right) .
\end{gathered}
$$

The value functions $V_{1}(z)$ and $V_{0}(z)$ are now completely defined. ${ }^{17}$ It is instructive to think about the different role played by the sunk cost $I$ and the overhead cost $\lambda_{1}$ in the presence of idiosyncratic shocks to a firm's efficiency. Under $I$, nonexporters are continuously comparing the value of becoming exporters, $V_{1}(z)-I / \lambda_{0}$, with the value of choosing the status quo $V_{0}(z)$. At $z=z_{H}$, these two values match and nonexporters are indifferent between switching to export and continuing with the status quo. If $z$ rises above $z_{H}$ it becomes strictly preferable to export. However, if, as a consequence of a series of negative shocks, $z$ falls below $z_{H}$ exporters do not switch their status (even if current export profits are negative) because the payoffs to be compared are now different: the value of exiting the export market is $V_{0}(z)$ and the value of choosing the status quo is $V_{1}(z)$. At $z=z_{H}$, for example, $V_{1}\left(z_{H}\right)>V_{0}\left(z_{H}\right)$, since the export entry cost $I / \lambda_{0}$ has already been sunk. When there are no sunk export costs but only overhead export costs (i.e. $I$ is replaced by $\lambda_{1}$ ), the value of becoming an exporter, being always $V_{1}(z)$, does not depend on the firm current export status. In this case, the cutoffs $z_{L}$ and $z_{H}$ coincide and firms start and stop exporting at this unique efficiency threshold.

\subsection{Equilibrium Efficiency Densities}

This section shows how to determine the equilibrium efficiency densities $f(z), f_{0}(z)$, and $f_{1}(z)$ and the corresponding probability densities $p(z), p_{0}(z)$, and $p_{1}(z)$.

The overall efficiency density, $f(z)$. As mentioned above, at each point in time, there is a measure $M_{E}$ of new firms that enter with efficiency $z_{0}=\bar{z}$. Consider the life of one of these firms. After entering at $\bar{z}$, this firm's efficiency evolves, as the firm ages, according to the stochastic process specified in equation (2). This means that, for each age level $a$ of the firm, there is a corresponding efficiency density describing how likely it is that the firm reaches a particular efficiency level $z_{a}$. The following partial differential equation, also known as the

\footnotetext{
${ }^{17}$ It can be helpful to briefly compare this dynamic programming problem to the one analyzed by Dixit (1989). Our problem nests Dixit's 1989 model, with two main differences. First, besides an entry and an exit cutoff $\left(z_{H}\right.$ and $z_{L}$, respectively), we need to determine a second exit cutoff $\left(z_{D}\right)$. This explains the presence of the additional value-matching and smooth pasting conditions (25) and (28). Second, while in Dixit (1989) the firm's cash flow from the investment only depends on the Brownian motion variable, in our setting it also depends on $X$, which can be interpreted as a proxy for market size. This is why we need an extra condition, namely the free entry condition, (16), in order to pin down the level of the cash flow.
} 
"Kolmogorov forward equation", allows us to find precisely such a density function, which we denote as $f(a, z) 18$

$$
\frac{\partial f(a, z)}{\partial a}=-\delta f(a, z)-\mu \frac{\partial f(a, z)}{\partial z}+\frac{1}{2} \xi^{2} \frac{\partial^{2} f(a, z)}{\partial z^{2}}
$$

for all $a>0$ and $z>z_{D}$. The first term on the right-hand side of equation (32) reflects the exogenous exit of firms. The remaining two terms describe how the density $f(a, z)$ evolves as a result of changes in the efficiency of a firm. There are two constraints that we want to impose on $f(a, z)$. The first is straightforward. As the firm's age goes to zero, the efficiency distribution implied by $f(a, z)$ must approach the efficiency distribution among entrants. Since $g($.$) is degenerate at \bar{z}$, this condition is

$$
\lim _{a \downarrow 0} \int_{z_{D}}^{s} f(a, s) d s=\left\{\begin{array}{l}
0 \text { if } s<\bar{z} \\
1 \text { if } s>\bar{z}
\end{array}\right.
$$

Second, following the optimal strategy of the firm outlined in section (2.2), we require that there are no active firms with efficiency equal to the exit threshold $z_{D}$, i.e,

$$
f\left(a, z_{D}\right)=0
$$

for all $a>0$. The solution to equation (32), subject to the boundary conditions (33)-(34), is

$$
f(a, z)=e^{-\delta a} \psi(a, z \mid \bar{z})
$$

for all $a>0$ and all $z>z_{D}$, where

$$
\psi(a, z \mid \bar{z})=\frac{1}{\xi \sqrt{a}}\left[\phi\left(\frac{z-\bar{z}-\mu a}{\xi \sqrt{a}}\right)-e^{-\frac{\mu\left(\bar{z}-z_{D}\right)}{\xi^{2} / 2}} \phi\left(\frac{z+\bar{z}-2 z_{D}-\mu a}{\xi \sqrt{a}}\right)\right],
$$

and $\phi($.$) is the standard normal density 19$

Now we can make a second thought experiment and switch from a "one-firm/time-series" approach to a "multiple firms/cross-sectional" view. In the steady state of the economy outlined above, firms enter and exit at constant aggregate rates in such a way that the aggregate measure of firms, $M$, does not change. There is a continuum of infinitesimal firms. The underlying stochastic structure is assumed to be such that probability distributions for individual firm efficiency can be interpreted as cross-sectional distributions for the whole continuum of firms. In other words, we can interpret $f(a, z)$, described above, as a stationary density over efficiency and age describing the set of firms that are active in the equilibrium. More precisely, let

\footnotetext{
${ }^{18}$ Note that age increases deterministically with a unit drift (and no variance). See chapter 3 of Stokey (2009) or chapter 3 of Dixit and Pindyck (1994) for a treatment of Kolmogorov forward and backward equations.

${ }^{19}$ See Luttmer (2007) and chapter 1.8 in Harrison (1985).
} 
$f(a, z) M_{E}$ be the density, over efficiency and age, characterizing the set of firms that are active in the steady state. Since $M$ is the measure of firms, $f(a, z) M_{E}$ has measure $M / M_{E}$. Each firm that is active in the steady state is characterized by an efficiency level $z$ and an age level $a$. Each of these firms has entered at $\bar{z}$. Their efficiency has evolved according to different realizations of equation (2). Some firms have exited at $z_{D}$, others at efficiency levels above $z_{D}$ as a consequence of having been hit by the exogenous shock with probability $\delta$. The set of exiting firms has been replaced by a new cohort of firms entering at $\bar{z}$. The efficiency density for each cohort of age $a$ is described as $f(a, z)$. The marginal density of $f(a, z)$ with respect to $z$ describes the efficiency of all the firms, independently from which cohort they belong to:

$$
f(z)=\int_{0}^{\infty} f(a, z) d a=-\frac{1}{\mu} \frac{\nu-\nu_{*}}{\nu+\nu_{*}}\left[\frac{\min \left\{e^{\left(\nu_{*}+\nu\right)\left(z-z_{D}\right)}, e^{\left(\nu_{*}+\nu\right)\left(\bar{z}-z_{D}\right)}\right\}-1}{e^{\nu_{*}\left(\bar{z}-z_{D}\right)} e^{\nu\left(z-z_{D}\right)}}\right],
$$

where

$$
\nu=-\frac{\mu}{\xi^{2}}+\sqrt{\left(\frac{\mu}{\xi^{2}}\right)^{2}+\frac{\delta}{\xi^{2} / 2}}, \quad \nu_{*}=\frac{\mu}{\xi^{2}}+\sqrt{\left(\frac{\mu}{\xi^{2}}\right)^{2}+\frac{\delta}{\xi^{2} / 2}}
$$

are positive constants. We need the following,

$$
\text { Assumption } 2: \quad \delta>\frac{\xi^{2}}{2}+\mu
$$

to guarantee that the mean of the equilibrium stationary distribution for $\exp (z)$ is finite. ${ }^{20}$ The intuition for the above assumption is that, as long as the killing rate, $\delta$, is high enough, the distribution has a finite mean even if the drift $\mu$ is positive.

Recall that $f(z)$ is not a probability density. In the appendix we derive the normalizing constant that is needed to transform the density $f(z)$ into the probability density $p(z) .{ }^{21}$ Note an important difference between our framework and Melitz (2003): in his case a firm's exit is linked to the constant exogenous probability of firm death, $\delta$, and, therefore, the exit process does not affect the shape of the equilibrium efficiency distribution, which inherits the characteristics of the entrants' efficiency distribution $g(z)$ (typically assumed to be a Pareto distribution). In our model, the probability of exiting from the foreign market is correlated with the firm's efficiency, and therefore this probability does affect the equilibrium efficiency distribution. A stationary

\footnotetext{
${ }^{20}$ The proof that the above condition is needed to ensure a finite mean is available upon request.

${ }^{21}$ We can now provide a more detailed explanation of the labor demand equation 20 . The measure of non-exporting firms that switch to export is intuitively equal to the flow of firms that pass the $z_{H}$ cutoff from below. In order to compute this, it is then necessary to use the density $f_{0}(z)$ and its evolution over time. As explained in Dixit and Pindyck (1994), the evolution of such a density is described by a Kolmogorov equation. It is possible to write a Kolmogorov equation similar to equation (32) for $f_{0}(a, z)$. The right-hand side of such a Kolmogorov equation describes exactly what happens to the density of nonexporting firms, for each $(a, z)$ pair, as time goes by. Since we are interested in the total flow of firms that passes in an interval centered at $z_{H}$, we need to integrate the right-hand side of the Kolmogorov equation over $z$ and $a$ and evaluate it at $z_{H}$. Therefore we obtain, recalling also that $f_{0}\left(z_{H}\right)=0$, the $\frac{1}{2} \xi^{2} \partial f_{0}\left(z_{H}\right) / \partial z$ term employed in equation 20 .
} 
efficiency distribution exists because new firms continuously enter the economy. Below we show that the upper tail of the efficiency (and size) density is nonetheless Pareto, consistent with the empirical evidence.

The efficiency density for exporters, $f_{1}(z)$. Each firm that is active in the steady state is also characterized by a trade status $j$. Firms transition from $j=0$ to $j=1$ (i.e. switch from nonexporting to exporting) when their efficiency reaches $z_{H}$ and transition from $j=1$ to $j=0$ (i.e. switch from exporting to nonexporting) when their efficiency crosses $z_{L}$ from above. At any point in time a fraction $p$ of firms is exporting. The measure of exporters, $p M$, is described by the density $f_{1}(z)$ (or by the corresponding probability density $p_{1}(z)$ ) that can be easily obtained following similar steps as those outlined above, but now with entry and exit points $z_{H}$ and $z_{L}$ instead of $\bar{z}$ and $z_{D}$,

$$
f_{1}(z)=-\frac{1}{\mu} \frac{\nu-\nu_{*}}{\nu+\nu_{*}}\left[\frac{\min \left\{e^{\left(\nu_{*}+\nu\right)\left(z-z_{L}\right)}, e^{\left(\nu_{*}+\nu\right)\left(z_{H}-z_{L}\right)}\right\}-1}{e^{\nu_{*}\left(z_{H}-z_{L}\right)} e^{\nu\left(z-z_{L}\right)}}\right] .
$$

Finally, the density $f_{0}(z)$ for the firms that do not export is equal to the difference between $f(z)$ and $f_{1}(z)$.

Probability densities. As in Luttmer (2007), the equilibrium probability density of $\exp (z)$ is Pareto in the upper tail with shape coefficient $\nu 2^{22}$ The probability density of $\exp (z)$ for exporters is also Pareto in the upper tail with shape coefficient $\nu{ }^{23}$ Since both a firm's exports and (variable) labor demand are proportional to $\exp (z)$, a simple change of variable establishes the following proposition.

Proposition 1 Both the probability density of export sales and of firm size are Pareto, with tail index $\nu /(\sigma-1)$, in the upper tail.

Proof. See the Appendix.

Eaton et al. (2011), using data from France, report that export sales distributions behave similarly to a Pareto distribution in the upper tail and more like a lognormal distribution in the lower tail independently of market size and extent of French participation. Export sales distributions are therefore similar to the overall firm size distribution, which the industry dynamics literature has already shown to be Pareto in the upper tail (e.g. Axtell 2001, Luttmer 2007). Proposition 1 therefore shows that in our model both the export sales distribution and the size distribution of firms preserve the same qualitative features observed in the data. Proposition 1 will prove to be handy below when we calibrate the model to the U.S. economy.

\footnotetext{
${ }^{22}$ Specifically, when $z>\bar{z}, \quad p(z)$ is equal to $A \exp (-\nu z)$, with $A=$ $\left\{e^{\nu z_{D}} \nu_{*} \nu\left[e^{\left(\nu_{*}+\nu\right)\left(\bar{z}-z_{D}\right)}-1\right]\right\} /\left\{\left(\nu+\nu_{*}\right)\left[e^{\nu_{*}\left(\bar{z}-z_{D}\right)}-1\right]\right\}$.

${ }^{23}$ Precisely, when $z>z_{H}$ the probability density $p_{1}(z)$ becomes $A_{1} \exp (-\nu z)$ where $A_{1}=$ $\left\{\exp \left(\nu z_{L}\right) \nu_{*} \nu\left[\exp \left[\left(\nu_{*}+\nu\right)\left(z_{H}-z_{L}\right)\right]-1\right]\right\} /\left\{\left(\nu+\nu_{*}\right)\left[\exp \left[\nu_{*}\left(z_{H}-z_{L}\right)\right]-1\right]\right\}$.
} 
Using the probability densities $p(z)$ and $p_{1}(z)$, it is easy to show that the fraction of exporters is equal to

$$
p=\frac{\int_{z_{H}}^{\infty} p(z) d z}{\int_{z_{H}}^{\infty} p_{1}(z) d z}=\frac{\frac{e^{(\nu *+\nu)\left(\bar{z}-z_{D}\right)}-1}{e^{\nu *\left(\bar{z}-z_{D}\right)}-1} e^{\nu z_{D}}}{\frac{e^{\left(\nu_{*}+\nu\right)\left(z_{H}-z_{L}\right)}-1}{e^{\nu *\left(z_{H}-z_{L}\right)}-1} e^{\nu z_{L}}} .
$$

The intuition for the first equality is the following. Along the $\left(z_{H}, \infty\right)$ range, both the overall efficiency probability density $p(z)$ and the probability density for exporters $p_{1}(z)$ are positive. Since along this range all firms are exporters, the ratio between $p(z)$ and $p_{1}(z)$ should be equal to the fraction of exporter, $p$.

\section{Numerical Analysis}

In this section, we calibrate the model to match relevant statistics of firms' turnover and export dynamics for the U.S. economy, and explore its properties numerically. We perform this analysis in order to provide an estimate of the sunk and overhead costs of exporting, to quantify the band of inaction, and analyze how different forms of trade liberalization (e.g. reduction in sunk or overhead trade costs) affect selection and persistence in export status.

The equilibrium system (28)-(31) in the four endogenous variables $z_{D}, z_{L}, z_{H}$ and $X$ features 13 parameters that must be calibrated: $\rho, \delta, \sigma, \tau, L, \bar{z}, \xi, \mu, \lambda_{E}, \lambda_{0}, \lambda_{1}, \nu$ and $I$. The discount rate $\rho$ is equal to the interest rate in steady state, thus we set it to 0.05 , as standard in the business cycle literature. Using U.S. Census 2004 data, we set $\delta$ to 0.09 , to match the average annual death rate for enterprises in manufacturing observed in the 1998-2004 period. ${ }^{24}$ We set $\sigma=7.69$ to match a markup of 15 percent, an intermediate value in the range of estimates reported in Basu (1996) 25 We set $\tau=1.3$, to match 30 percent variable trade costs, in line with values in Obstfeld and Rogoff (2001). We normalize the population level $L$ to 1 and the common entry level efficiency $\bar{z}$ to 2 , without loss of generality.

Brownian motion parameters. The parameters of the Brownian motion, $\mu$ and $\xi$, can be calibrated in the following way. The model implies that the average growth rate of variable employment conditional on survival is a function of $\mu$ and $\xi{ }^{26}$

$$
g r=(\sigma-1) \mu+\frac{1}{2}(\sigma-1)^{2} \xi^{2} .
$$

This relies on the fact that employment varies, in the model, only because of the efficiency

\footnotetext{
${ }^{24}$ For each year the death rates are computed as follows: taking year 2000 as an example, the death rate is the ratio of firms dead between March 2000 and March 2001 to the total number of firms in March 2000. The data can be downloaded at http://www.sba.gov/advo/research/data.html.

${ }^{25}$ Anderson and Wincoop (2004) reports estimates of the elasticity of substitution between 5 and 10 , hence our calibrated value is in this range.

${ }^{26}$ See the Appendix.
} 
shocks. ${ }^{27}$ The U.S. Census data compiled by the Small Business Administration show that employment among firms with 500 or more employees grows at an annual rate of 0.0036 over the 1988-2006 period (Luttmer, 2012). We need a second equation in the two unknowns $\mu$ and $\xi$. The model predicts a stationary employment distribution that is Pareto in the upper tail with tail index $\nu /(\sigma-1)$ (Proposition 1). Using the definition of $\nu$ in equation (36), we can find a second relationship between $\mu$ and $\xi$,

$$
\mu=\frac{\delta}{\nu}-\frac{\nu}{2} \xi^{2}
$$

The employment size distribution of U.S. firms is stable over time and close to Pareto for firms with more than 20 employees. A point estimate of the tail index $\nu /(\sigma-1)$ is about 1.06 (Luttmer, 2007 and 2012), which we use to calibrate $\nu$ obtaining the value 7.093. Hence, solving the two equations above with respect to $\mu$ and $\xi$ leads to

$$
\begin{gathered}
\xi=\sqrt{\frac{\frac{2}{\sigma-1}\left[(\sigma-1) \frac{\delta}{\nu}-g r\right]}{\nu-(\sigma-1)}} \\
\mu=\frac{1}{\sigma-1}\left[g r-\frac{1}{2}(\sigma-1)^{2} \xi^{2}\right] .
\end{gathered}
$$

Using the calibrated values for $\sigma, \delta, \nu$ we obtain the values $\xi=0.2459$ and $\mu=-0.2019$.

Overhead and sunk costs. Parameters $\lambda_{E}, \lambda_{0}, \lambda_{1}$, and $I$ are jointly calibrated to match the following four key statistics of the U.S. economy. Djankov et al. (2002) find that the total regulatory entry cost for the United States in 1999 were 1.6 percent of GDP per capita. This statistics is particularly relevant for the sunk entry cost, since in the model total entry costs as a share of income are

$$
m_{1}=M_{E} w \lambda_{E} / Y
$$

where $m_{1}$ stands for the first moment/target used in the calibration, and $M_{E}, w$, and $Y$ are derived in Section 2.3. Using 2004 U.S. Census data we find that the average death rate of small enterprises (i.e. between one and nine workers) is 11.74 percent in the period 1998-2004: we target this moment since it is particularly relevant for the fixed operating cost $\lambda_{0}$. In terms of the model this second moment is 28

$$
m_{2}=\frac{1}{2} \xi^{2} \frac{1}{1-p} \frac{\nu_{*} \nu}{e^{\nu_{*}\left(\bar{z}-z_{D}\right)}-1} .
$$

Note that the closer the exit cutoff $z_{D}$ is to the entry point $\bar{z}$, the higher is the chance that firms will eventually exit because of a sequence of bad efficiency shocks, and therefore, the

\footnotetext{
${ }^{27}$ Shocks to efficiency are converted in shocks to employment (and to sales) through the elasticity of susbtitution. This explains the presence of $\sigma$.

${ }^{28}$ See the Appendix.
} 
higher is $m_{2}$. Bernard and Jensen (2004a) using U.S. Census data show that 12.6 percent of exporters become nonexporters on average in the period 1984-1992. We choose this as a target in calibrating the fixed operating cost of exporting $\lambda_{1}$ and the sunk cost $I$. In the model the percentage of exporting firms ceasing to export is:29

$$
m_{3}=\frac{1}{2} \xi^{2} \frac{\nu_{*} \nu}{e^{\nu_{*}\left(z_{H}-z_{L}\right)}-1}
$$

Again, note that the closer the entry point $z_{H}$ is to the export exit cutoff $z_{L}$, the higher is the chance that exporters will eventually stop exporting because of a sequence of bad efficiency shocks, and therefore, the higher is $m_{3}$. Finally Bernard et al. (2003) find that 21 percent of U.S. manufacturing firms in the 1992 Census data are exporters. This is our additional target for the sunk cost of exporting $I$ and overhead costs $\lambda_{1}$. This fourth target in the model is represented by $m_{4}=p$, where the fraction of exporters $p$ is defined in equation (38).

Calibration fit. These targeted moments are enough to identify the four parameters $\lambda_{E}$, $\lambda_{0}, \lambda_{1}$, and $I$ only up to a scale factor. The calibrated parameters $\lambda_{E}, \lambda_{0}, \lambda_{1}$, and $I$ are such that the predicted moments are fairly close to the actual ones, as shown in Table 1 below.

\section{[Table 1 about here]}

The calibrated parameter values show two interesting features. First, the sunk cost of starting up a firm, $\lambda_{E}$, is about 20 times higher than the sunk cost of exporting, $I$, for an existing firm. Second, the export overhead cost, $\lambda_{1}$, is about 2.5 times higher than the domestic counterpart, $\lambda_{0}$. Both results are reasonable. Setting up a firm is probably a much harder task than entering a foreign market as an already established business. Moreover, the cost of maintaining a presence in the foreign market is likely to be higher than the cost of maintaining a presence in the domestic market.

The calibration fit and, therefore, the above results are invariant to a proportional rescaling of the four cost parameters, $\lambda_{E}, \lambda_{0}, \lambda_{1}$, and $I$. Since the different types of fixed exporting costs play a key role in this paper, it could be insightful to provide U.S. dollar values for these costs and compare them with existing estimates. With the aid of an extra moment we can provide an approximate estimate of the fixed costs. Irarrazabal et al. (2009) show that the export overhead cost for Norwegian firms ranges between $\$ 1,439$ and $\$ 13,118$ with an average across destinations of $\$ 5,202$ in 1992 dollars 30 We can use the figures above as an approximate reference for the value of $\lambda_{1}$ in our model and get an idea of the dollar value of the sunk export cost $I$. If we constrain the value in dollars of $\lambda_{1}$ to approximate the average export overhead

\footnotetext{
${ }^{29}$ See the Appendix.

${ }^{30}$ See Table 3 in Irarrazabal et al. (2009). Since that paper uses 2004 data and our calibration mainly uses 1992 data, we convert their figures in 1992 dollars using the U.S. GDP deflator for those years.
} 
cost figure in Norwegian data, the export sunk cost predicted by our model is $\$ 476,72641$ Das et al. (2007) estimate the fixed cost to enter the export market for a few relevant manufacturing sectors in Colombia, finding values ranging from $\$ 416,584$ to $\$ 520,730$, which are close to our prediction. 32

In the top two panels of Figure 2 we use the calibrated parameters to plot the value of a nonexporting firm, $V_{0}(z)$, and of an exporter, $V_{1}(z)$, defined in Section 2.2 and 2.4, both as a function of efficiency $z$. We also show the thresholds $z_{D}, z_{L}$, and $z_{H}$. Since the value functions increase very rapidly as $z$ approaches the export entry cutoff $z_{H}$, we first show a plot of $V_{0}(z)$ and $V_{1}(z)$ for $z$ between $z_{D}$ and a value slightly above $z_{L}$ (top-left panel), and then plot the same functions for values of efficiency close to $z_{H}$ (top-right panel). As expected, $V_{0}(z)$ and $V_{1}(z)$ are both increasing in $z$, they have the same value for $z \leq z_{L}$ as stated by the equilibrium condition (14), and they depart for $z>z_{L}$ where $V_{1}(z)>V_{0}(z)$, as stated by the equilibrium condition (12). The bottom-left panel of Figure 2 shows the difference between $V_{1}(z)$ and $V_{0}(z)$. Along the $\left[z_{L}, z_{H}\right]$ interval, we can interpret this difference as the firm's incremental value of being an exporter, that is, how much more it is worth when it sells in the foreign market than when it does not. As required by conditions (7) and (14) derived in Section 2.2, such an incremental value is zero at $z_{L}$ and equals the sunk cost of exporting, $I / \lambda_{0}$, at $z_{H}$. Moreover, as required by conditions (8) and (15), the slope of $V_{1}(z)$ and $V_{0}(z)$ is the same at the thresholds $z_{L}$ and $z_{H}$.

\section{[Figure 2 about here]}

Figure 3 depicts the stationary distributions of efficiency by export status. We show the overall efficiency distribution, $p(z)$, and the distribution for exporters, $p_{1}(z)$.

\section{[Figure 3 about here]}

First, notice that both distributions, as shown analytically in Section 2.5, are Pareto in the upper tail. Given the assumptions on the production function and preferences, this implies that also the corresponding sales and size distributions are Pareto in the upper tail, as described in

${ }^{31}$ The dollar values of each fixed cost can be computed as follows,

$$
\frac{w F C}{Y}\left(Y_{1992}^{U S} * m_{1992}^{U S}\right)
$$

where $F C=\left(\lambda_{E}, \lambda_{0}, \lambda_{1}, I\right)$ is the vector of the costs as a share of income in the model. $Y_{1992}^{U S}$ is U.S. GDP in 1992, equal to 6.29 trillions (Bureau of Economic Analysis, National Income and Product Accounts, http://www.bea.gov/iTable/iTable.cfm?ReqID=9\&step=1), which is chosen because for many of the calibration targets we used 1992 U.S. Census data from Bernard et al. (2003). Since, the calibration focuses on firm-level data in manufacturing, we use the manufacturing share of GDP $m_{1992}^{U S}$ as a measure of the size of the economy. In 1992 the percentage of U.S. GDP coming from manufacturing is about 18.3 (World Development Indicators, http://data.worldbank.org/data-catalog/world-development-indicators).

${ }^{32}$ Since their data are in 1986 dollars we have used the U.S. GDP deflator to convert to 1992 dollars, to facilitate comparison. 
Proposition 1. As mentioned above, this is consistent with evidence from firm-level data (e.g. Axtell 2001, and Eaton et al. 2011). The kink at $z=\bar{z}$ for $p(z)$ is a result of firm entry that takes place at $\bar{z}$. Similarly, the kink at $z=z_{H}$ for $p_{1}(z)$ is a result of the entry into export that takes place at $z_{H}$.

Second, the interval $\left(z_{L}, z_{H}\right)$ describes a wide band of inaction where the distribution of exporters and nonexporters overlap, i.e. some exporters are less efficient than some nonexporters. This comes to grips with plant level facts (for example Bernard et al. 2003). Eaton et al. (2011), introducing firm- (and market-) specific fixed cost and demand shocks into a static framework, also provide a model that is consistent with overlapping exporter and nonexporter distributions. In our model, the overlap instead is due to efficiency shocks and sunk export entry costs, leading each single firm to start and stop exporting at different $z$ levels. This is consistent with Bernard and Jensen (2004b) who, using U.S. data for the 1984-92 period to track firms over time, find that firms start and stop exporting at different productivity levels, with exporters exiting at a productivity level one-third below the productivity level at which firms start exporting. Moreover, they find that firms exiting from the export market show a comparable deterioration of their productivity levels. In our benchmark calibration the efficiency difference between entrants and exiting firms in the export market is substantial as well: the $z_{H} / z_{L}$ ratio is approximately 1.4, suggesting that exiting exporters lose about 29 percent of the efficiency they had at entry.

Another way to reconcile the presence of a wide band of inaction with the data is in terms of persistence in export status. The literature on hysteresis (e.g. Baldwin and Krugman 1989) has advanced the idea that nonexporters must incur a sunk entry cost in order to enter the foreign market. Roberts and Tybout (1997) find strong evidence for the presence of sunk costs and conclude that prior export experience increases the probability of exporting by as much as 60 percentage points. Bernard and Jensen (2004a), using data for U.S. plants, find that the percentage of exporters in 1984 who were also exporters in 1985 is 85 percent. In our baseline calibration the share of exporters that keep exporting between two periods is very close, being about 87 percent.

\subsection{Globalization Scenarios}

In this section we explore the model further by studying and comparing the implications of reductions in the two types of fixed trade costs: the sunk export entry cost $I$, and the overhead export cost $\lambda_{1}$. This is a relevant exercise since these barriers are isomorphic in the standard Melitz (2003) model. In the two cases analyzed below, the initial steady state is the one of the baseline calibration described in the previous section. We start by considering the effects of a 10 percent reduction in the sunk export entry cost $I$.

[Figure 4 about here] 
The top three panels of Figure 4 report the change (to be read from right to left) of the three cutoffs, $z_{D}, z_{L}$, and $z_{H}$. The intuition behind these movements is as follows: When the sunk export entry cost decreases, uncertainty about future efficiency matters less. An exporter that receives a bad shock is more likely to stop exporting. The risk of having to repay the sunk cost in the future is less important because the magnitude of this cost is lower. This intuition explains the increase in $z_{L}$. Similarly, a nonexporter that receives a positive shock is more likely to start exporting since it is now easier and less risky to cover the sunk cost with future export revenues. This explains the decrease in $z_{H}$. Finally, the increase in the $z_{D}$ cutoff has the same explanation as in Melitz (2003): the increased labor demand by the more efficient firms and new entrants bids up the real wage and forces the least efficient firms to exit. In a nutshell, when the sunk export entry cost is reduced, it is easier for a nonexporter to become an exporter, it is easier for an exporter to stop exporting, and it is more difficult for less efficient firms to survive. Given the reduction in $z_{H}$ and the increase in $z_{L}$, the band of inaction narrows. The status quo therefore becomes a less frequent choice, and hysteresis in exporting becomes more attenuated. The bottom central panel of Figure 4 shows that the share of exporters that exit the foreign market increases, i.e. export participation becomes less persistent. Finally, the share of exporters (out of all active firms) increases. This result is not straightforward since, as mentioned above, on the one hand, it becomes easier to put in place the investments needed to enter the foreign market $\left(z_{H}\right.$ decreases) but, on the other hand, it also becomes easier to exit those markets whenever conditions get worse $\left(z_{L}\right.$ increases). The former margin dominates quantitatively leading to a larger share of exporters.

\section{[Figure 5 about here]}

Figure 5 shows what happens to the key variables of the model when the overhead export cost $\lambda_{1}$ is reduced by 10 percent. The top panel shows that both the export entry cutoff $z_{H}$ and the export exit cutoff $z_{L}$ decrease while the exit cutoff $z_{D}$ increases. The movement in the latter can be explained along the same lines as before. The intuition for the change in $z_{L}$ and $z_{H}$ instead is the following. When the overhead export cost decreases, exporters, conditional on their current efficiency level, enjoy higher profits from their current sales and are more likely to be able to cover the fixed trade cost in the future as well. This explains why $z_{L}$ decreases. On the contrary, nonexporters are more likely to receive a positive shock to efficiency that is big enough to make it profitable to start exporting. This explains why also $z_{H}$ decreases. The band of inaction, measured by $z_{H}-z_{L}$, widens as the reduction in $z_{L}$ is larger than the reduction in $z_{H}$. The intuition for the difference in the rate of reduction of $z_{H}$ and $z_{L}$ is that the decision to start exporting is less sensitive to a change in the overhead export cost once a sunk export cost is in place. As a consequence, $z_{H}$ decreases when $\lambda_{1}$ does but not as fast as $z_{L}$. Since the band of inaction is now wider, those firms that already export are less likely to stop doing so, leading to more hysteresis in exporting. The bottom central panel of Figure 5 therefore shows 
a decrease in the share of exporters that become nonexporters. When the export overhead cost decreases, it is easier to start exporting but the decision to stop becomes less obvious. Finally, as in the previous case, the share of exporters increases. This time this is a less ambiguous result since both export cutoffs decrease.

Overall, the main difference between a reduction in the sunk export entry cost $I$ and the export overhead cost $\lambda_{1}$ is its effect on the band of inaction and therefore on the persistency of the export status. Trade liberalization via a reduction in sunk export costs reduces hysteresis, while the opposite happens when liberalization takes place through a reduction in overhead export costs. The new exporters margin, the increase in the share of exporters produced by trade liberalization, is about 10 percent with a reduction of $I$ and about 1 percent with a reduction of $\lambda_{1}$.

\section{Conclusions}

In this paper we introduce persistent idiosyncratic efficiency shocks in a continuous-time model of trade with heterogeneous firms. We show that the presence of sunk export entry costs and efficiency uncertainty gives rise to hysteresis in export market participation and provides a framework to study export dynamics in a general equilibrium environment. In our model, a firm's efficiency is not a sufficient statistics for its export status since a firm's export decisions are history-dependent. Firms start exporting at a certain efficiency level, but may remain in the foreign market even after their efficiency has fallen below the level it was at when they entered the market. Moreover, the model reflects features of firm birth, growth, and export market entry and exit observed in the data.

A calibrated version of the model is used to provide estimates of the size of the sunk cost of exporting, and of a firm's persistence in export status. Moreover, numerical simulations are used to show how different modes of globalization, in the form of a reduction in the sunk export entry cost as opposed to a reduction in the export overhead cost, affect firms' selection and persistence in export status. In this sense, our model formalizes a very natural link between two branches of the literature: the literature on hysteresis, focusing on explaining why the same trade and exchange rate policies can have strikingly different effects in different countries or time periods, and the new trade theory, emphasizing the selection effects of trade policies.

One limitation of our theoretical and quantitative analysis is the focus on trade among symmetric countries. This implies, for instance, that we cannot explore the effects of unilateral trade liberalization episodes on firm's selection and on the persistence in export status. Moreover, a symmetric country model cannot be used to explain the substantial variation in export entry (across markets) and in sales conditional on entering a market found in the data (e.g. Eaton et al., 2011). In on-going research, we are exploring a number of extensions of our framework, including the case of multiple asymmetric countries. 


\section{References}

[1] Amador, J., Opromolla, L. D., 2013. Product and Destination Mix in Export Markets. Review of World Economics 149 (1), forthcoming.

[2] Alessandria, G., Choi, H., 2012. Establishment Heterogeneity, Exporter Dynamics, and the Effects of Trade Liberalization. Federal Reserve Bank of Philadelphia Working Paper No. 11-19/R. URL: http://www.phil.frb.org/research-and-data/publications/workingpapers/2011/wp11-19R.pdf

[3] Anderson, J., van Wincoop, E., 2004. Trade costs. Journal of Economic Literature 42 (3), $691-751$.

[4] Antràs, P., 2004. Advanced Topics in International Trade: Firms and International Trade. Lecture notes, Harvard University.

[5] Arkolakis, K., 2010. Market Penetration Costs and the New Consumers Margin in International Trade. Journal of Political Economy 118 (6), 1151-1199.

[6] Atkeson, A., Burstein, A., 2010. Innovation, Firm Dynamics, and International Trade. Journal of Political Economy 118 (3), 433-484.

[7] Axtell, R. L., 2001. Zipf Distribution of U.S. Firm Sizes. Science 293 (5536), 1818-1820.

[8] Baldwin, R., 1990. Hysteresis in Trade. Empirical Economics 15 (2), 127-142.

[9] Baldwin, R., Krugman, P., 1989. Persistent Trade Effects of Large Exchange Rate Shocks. The Quarterly Journal of Economics 104 (4), 635-654.

[10] Basu, S., 1996. Procyclical Productivity: Increasing Returns or Cyclical Utilization? Quarterly Journal of Economics 111(3), 709-751.

[11] Bernard, A. B., Jensen, J. B., 1995. Exporters, Jobs, and Wages in U.S. Manufacturing: 1976-1987. Brookings Papers on Economic Activity: Microeconomics, 67-119.

[12] Bernard, A. B., Jensen, J. B., 2004a. Why Some Firms Export. The Review of Economics and Statistics $86(2), 561-569$.

[13] Bernard, A. B., Jensen, J. B., 2004b. Exporting and Productivity in the USA. Oxford Review of Economic Policy 20 (3), 343-357.

[14] Bernard, A. B., Eaton, J., Jensen, J. B., Kortum, S., 2003. Plants and Productivity in International Trade. American Economic Review 93(4),1268-1290. 
[15] Bernard, A., Wagner, J., 2001. Export Entry and Exit by German Firms. Welktwirtschaftliches Archiv Bd. 137 H. 1, 105-123.

[16] Campa, J., 2004. Exchange Rates and Trade: How Important is Hysteresis in Trade? European Economic Review 48 (3), 527-548.

[17] Costantini, J. A., Melitz, M. J., 2008. The Dynamics of Firm-Level Adjustment to Trade Liberalization. In: Helpman, E., Marin, D., Verdier, T. (Eds.). The Organization of Firms in a Global Economy. Harvard University Press, Cambridge, MA, 107-141.

[18] Das, S., Roberts, M. J., Tybout, J. R., 2007. Market Entry Costs, Producer Heterogeneity, and Export Dynamics. Econometrica 75 (3), 837-873.

[19] Dixit, A., 1989. Entry and Exit Decisions under Uncertainty. Journal of Political Economy $97(3), 620-38$.

[20] Dixit, A., Pindyck, R. S., 1994. Investment under Uncertainty. Princeton University Press, Princeton NJ.

[21] Djankov, S., Lopez-De-Silanes, F., La Porta, R., Shleifer, A., 2002. The Regulation of Entry. Quarterly Journal of Economics 117 (1), 1-37.

[22] Eaton, J., Eslava, M., Kugler, M., Tybout, J., 2008. The Margins of Entry into Export Markets: Evidence from Colombia. In: Helpman, E., Marin, D., Verdier, T. (Eds.). The Organization of Firms in a Global Economy. Harvard University Press, Cambridge, MA, 231-272.

[23] Eaton, J., Kramarz, F., Kortum, S., 2011. An Anatomy of International Trade: Evidence from French Firm. Econometrica 79 (5), 1453-1498.

[24] Ghironi, F., Melitz, M. J., 2005. International Trade and Macroeconomic Dynamics with Heterogeneous Firms. Quarterly Journal of Economics 120 (3), 865-915.

[25] Harrison, M. J., 1985. Brownian Motion and Stochastic Flow Systems. John Wiley, New York.

[26] Helpman, E., Melitz, M. J., Yeaple, S. R., 2004. Export Versus FDI with Heterogeneous Firms. American Economic Review 94 (1), 300-316.

[27] Impullitti, G., Licandro, O., 2010. Trade, Firm Selection, and Innovation: the Competition Channel. Barcelona GSE Working Papers Series 495. URL: http://www.iae.csic.es/investigatorsMaterial/a111111122530archivoPdf8766.pdf 
[28] Irarrazabal, A., Moxnes, A., Opromolla, L. D., 2009. The Margins of Multinational Production and the Role of Intrafirm Trade. CEPR Discussion Paper 7145. URL: http://www.cepr.org/pubs/dps/DP7145.asp

[29] Luttmer, E. G. J., 2007. Selection, Growth and the Size Distribution of Firms. Quarterly Journal of Economics 122 (3), 1103-44.

[30] Luttmer, E. G. J., 2012. Technology Diffusion and Growth. Journal of Economic Theory $147(2), 602-622$.

[31] Melitz, M. J., 2003. The Impact of Trade on Intra-Industry Reallocations and Aggregate Industry Productivity. Econometrica 71 (6), 1695-1725.

[32] Obstfeld, M., Rogoff, K., 2001. The Six Major Puzzle in International Macroeconomics: is there a Common Cause? In: Bernanke, B.S., Rogoff, K. (Eds.), NBER Macroeconomics Annual 15, MIT Press, Cambridge, MA, 339-390.

[33] Roberts, M. J., Tybout, J. R., 1997. The Decision to Export in Colombia: An Empirical Model of Entry with Sunk Costs. American Economic Review 87 (4), 545-564.

[34] Ruhl, K. J., 2008. The International Elasticity Puzzle in International Economics. New York University, Leonard N. Stern School of Business, Department of Economics Working Paper 08-30. URL: http://kimruhl.squarespace.com/storage/Ruhl_Elasticity.pdf

[35] Stokey, N. L., 2009. The Economics of Inaction: Stochastic Control Models with Fixed Costs. Princeton University Press, Princeton NJ. 
Table 1: Model Fit

\begin{tabular}{ccccc}
\hline \hline Targeted moments & & Benchmark model & Source & Data \\
Entry cost (share of GDP) & $m_{1}$ & 0.016 & Djankov et al. (2002) & 0.016 \\
Firms' death rate & $m_{2}$ & 0.121 & U.S. Census 2004 & 0.117 \\
Export-to-Nonexp. transition & $m_{3}$ & 0.126 & Bernard et al. (2004a) & 0.126 \\
Share of exporters & $m_{4}$ & 0.201 & Bernard et al. (2003) & 0.210 \\
\hline
\end{tabular}


Figure 1: Efficiency Sample Paths

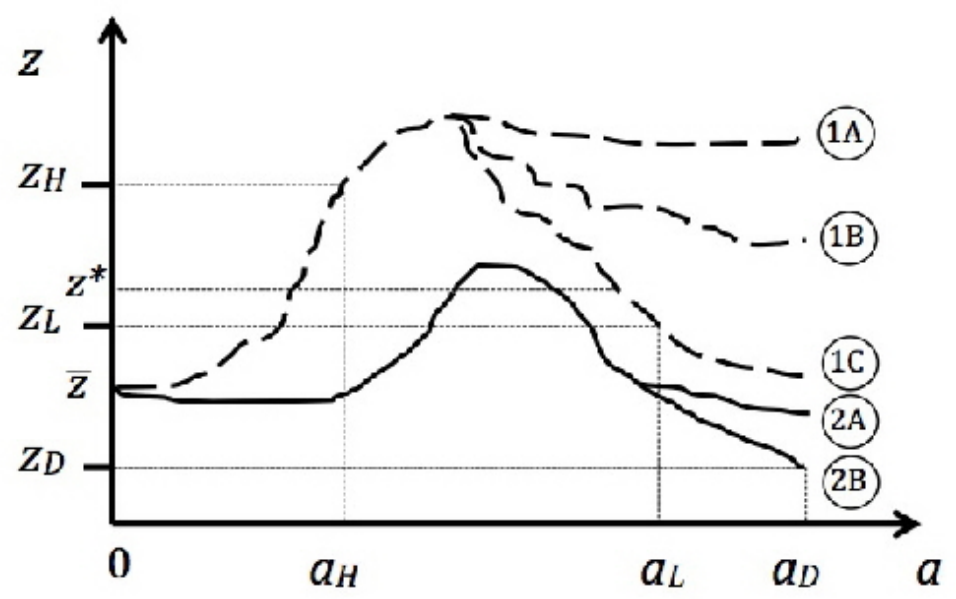

Source: Authors' calculations. 
Figure 2: Value Functions
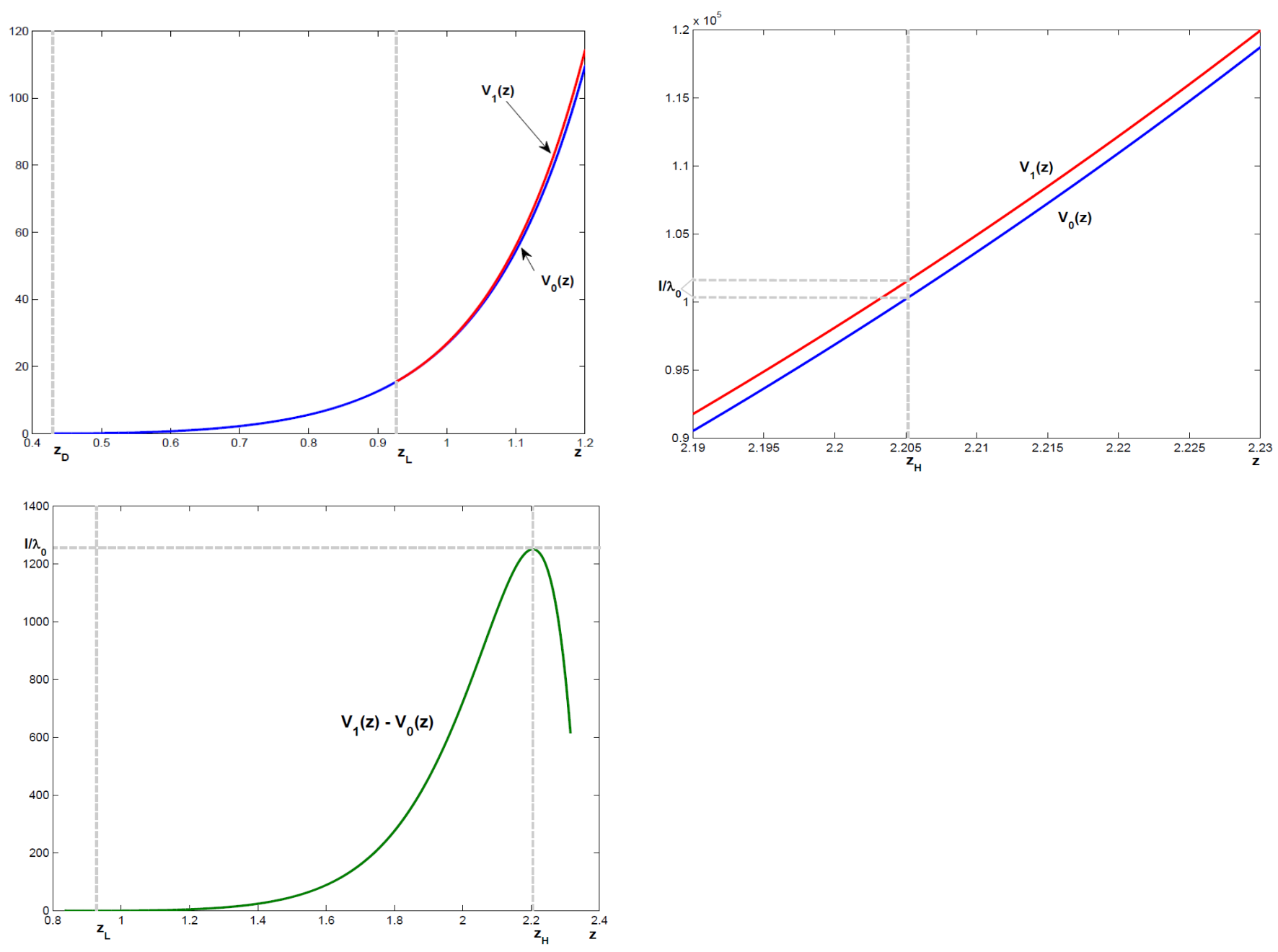

Source: Authors' calculations. 
Figure 3: Equilibrium Efficiency Distribution

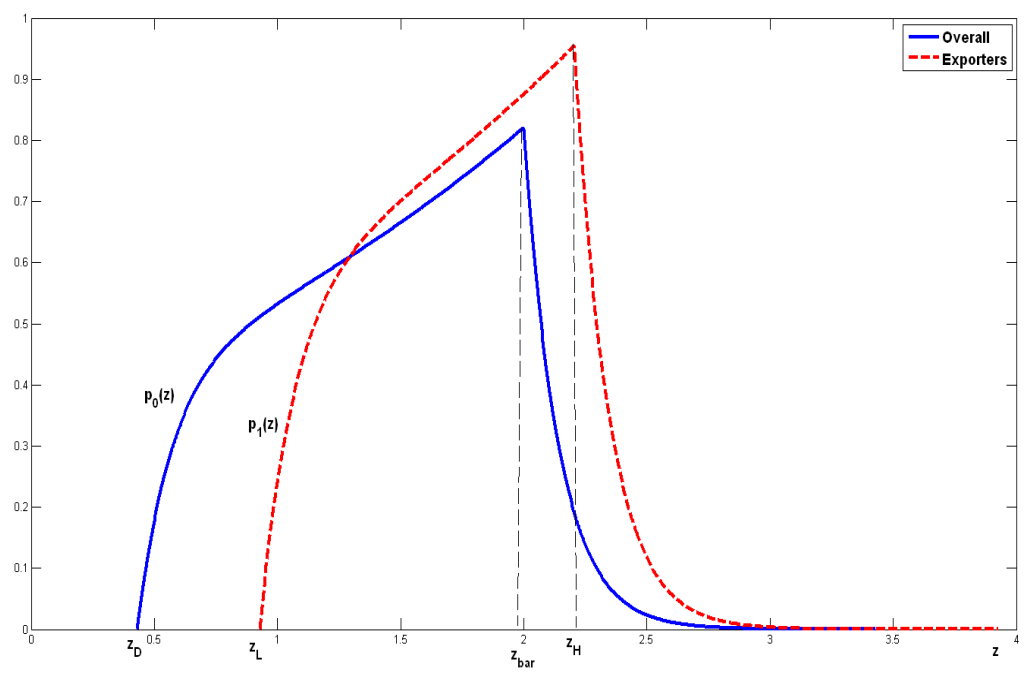

Source: Authors' calculations. 
Figure 4: Trade Liberalization: Reducing Sunk Export Costs
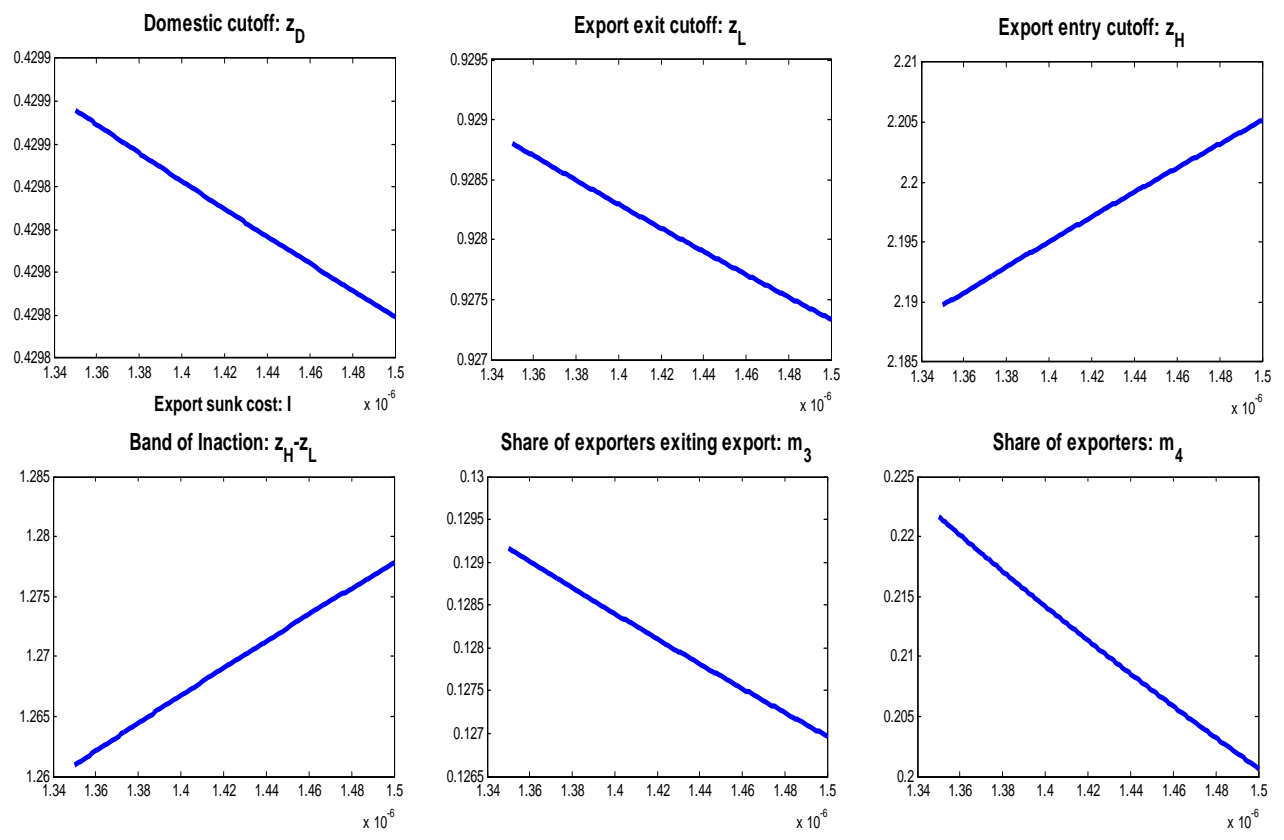

Source: Authors' calculations. 
Figure 5: Trade Liberalization: Reducing Overhead Export Costs
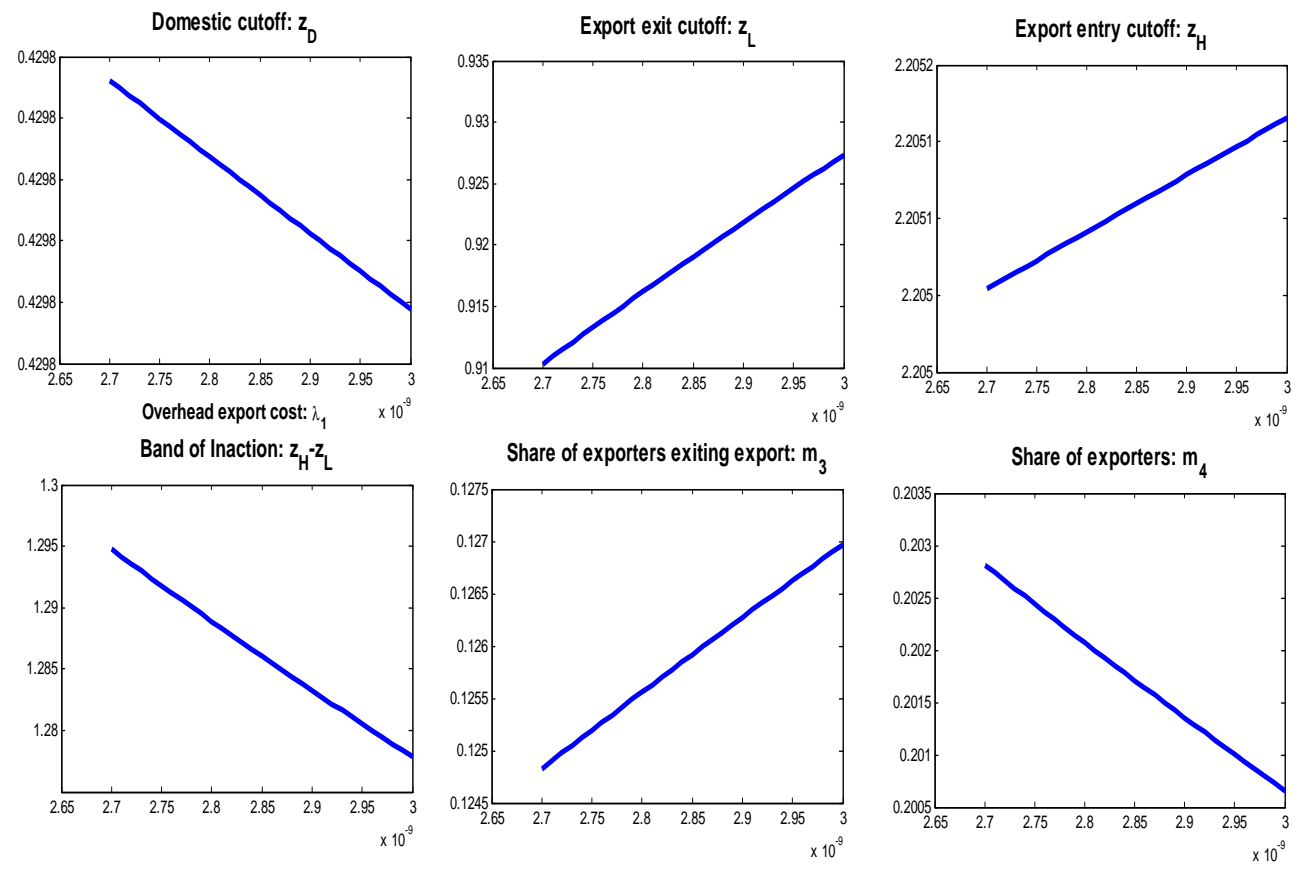

Source: Authors' calculations. 


\section{Appendix}

\subsubsection{Value Matching Conditions}

The three value-matching conditions of equations (25), (26), and (27) can be used to solve for the three constants, $A_{0}, A_{1}$, and $B_{0}$, as a function of the three cutoffs, $z_{D}, z_{L}, z_{H}$, and $X$. The three smooth pasting conditions and the free entry condition of equations (28), (29), (30), and (31) can then be used to solve for $z_{D}, z_{l}, z_{H}$, and of $X$. We can rewrite the three value-matching conditions as

$$
\begin{gathered}
\frac{1}{r^{*}} \pi_{0}\left(z_{D}\right)-\frac{1}{r^{*}}+A_{0} e^{-\theta z_{D}}+B_{0} e^{\theta_{*} z_{D}}=0 \\
\frac{1}{r^{*}}\left(1+\tau^{1-\sigma}\right) \pi_{0}\left(z_{L}\right)-\frac{1}{r^{*}} \frac{\lambda_{0}+\lambda_{1}}{\lambda_{0}}+A_{1} e^{-\theta z_{L}}=\frac{1}{r^{*}} \pi_{0}\left(z_{L}\right)-\frac{1}{r^{*}}+A_{0} e^{-\theta z_{L}}+B_{0} e^{\theta * z_{L}}, \\
\frac{1}{r^{*}} \pi_{0}\left(z_{H}\right)-\frac{1}{r^{*}}+A_{0} e^{-\theta z_{H}}+B_{0} e^{\theta_{*} z_{H}}=\frac{1}{r^{*}}\left(1+\tau^{1-\sigma}\right) \pi_{0}\left(z_{H}\right)-\frac{1}{r^{*}} \frac{\lambda_{0}+\lambda_{1}}{\lambda_{0}}+A_{1} e^{-\theta z_{H}}-\frac{I}{\lambda_{0}} .
\end{gathered}
$$

The first condition can be solved for $A_{0}$,

$$
A_{0}=\left[-B_{0} e^{\theta_{*} z_{D}}+\frac{1}{r^{*}}-\frac{1}{r^{*}} \pi_{0}\left(z_{D}\right)\right] e^{\theta z_{D}}
$$

Inserting the above into the second value-matching condition we get

$$
\begin{gathered}
A_{1}=\frac{1}{r^{*}}\left[-e^{\theta z_{L}}-\tau^{1-\sigma} \pi_{0}\left(z_{L}\right) e^{\theta z_{L}}+e^{\theta z_{D}}-\pi_{0}\left(z_{D}\right) e^{\theta z_{D}}+\frac{\lambda_{0}+\lambda_{1}}{\lambda_{0}} e^{\theta z_{L}}\right] \\
+B_{0}\left(e^{\theta_{*} z_{L}} e^{\theta z_{L}}-e^{\theta * z_{D}} e^{\theta z_{D}}\right) .
\end{gathered}
$$

Now inserting both the expression for $A_{0}$ and the one for $A_{1}$ in the third value-matching condition we get $B_{0}$ as a function of $z_{L}, z_{H}, X$ :

$$
B_{0}=\frac{\left[1+\tau^{1-\sigma} \pi_{0}\left(z_{H}\right)-\frac{\lambda_{0}+\lambda_{1}}{\lambda_{0}}\right] \frac{1}{r^{*}}-\left[1+\tau^{1-\sigma} \pi_{0}\left(z_{L}\right)-\frac{\lambda_{0}+\lambda_{1}}{\lambda_{0}}\right] e^{\theta z_{L}} e^{-\theta z_{H}} \frac{1}{r^{*}}-\frac{I}{\lambda_{0}}}{e^{\theta_{*} z_{H}}-e^{\theta_{*} z_{L}} e^{\theta z_{L}} e^{-\theta z_{H}}} .
$$

It is then easy to get $A_{0}$ and $A_{1}$.

\subsubsection{Aggregate Output}

Aggregate output is the sum of revenues for all exporting and non-exporting firm. Recalling that, under our assumptions, flow profits are a fraction $1 / \sigma$ of revenues, 


$$
\begin{aligned}
Y & =\sigma\left[\int_{z_{D}}^{\infty} \pi_{0}(z) w \lambda_{0} f(z) d z+p \int_{z_{L}}^{\infty} \pi_{1}(z) w \lambda_{0} f_{1}(z) d z\right] M_{E} \\
& =\left(\frac{\sigma-1}{\sigma}\right)^{\sigma-1} w^{1-\sigma} C\left[\int_{z_{D}}^{\infty} e^{(\sigma-1) z} f(z) d z+p\left(1+\tau^{1-\sigma}\right) \int_{z_{L}}^{\infty} e^{(\sigma-1) z} f_{1}(z) d z\right] M_{E}
\end{aligned}
$$

so that, using $X=w^{1-\sigma} C / w$, yields

$$
\frac{Y}{w}=X\left(\frac{\sigma-1}{\sigma}\right)^{\sigma-1}\left[\int_{z_{D}}^{\infty} e^{(\sigma-1) z} f(z) d z+p\left(1+\tau^{1-\sigma}\right) \int_{z_{L}}^{\infty} e^{(\sigma-1) z} f_{1}(z) d z\right] M_{E} .
$$

\subsubsection{The Efficiency Marginal Density $f(z)$}

Consider the density $f(a, z)=e^{-\delta a} \psi(a, z \mid \bar{z})$. The marginal $f(z)$ is

$$
f(z)=\int_{0}^{\infty} e^{-\delta a} \psi(a, z \mid \bar{z}) d a=I_{1}-e^{-\frac{\mu\left(\bar{z}-z_{D}\right)}{\xi^{2} / 2}} I_{2}
$$

where

$$
\begin{aligned}
& I_{1}=\int_{0}^{\infty} \frac{e^{-\delta a}}{\xi \sqrt{a}} \phi\left(\frac{z-\bar{z}-\mu a}{\xi \sqrt{a}}\right) d a \text { and } \\
& I_{2}=\int_{0}^{\infty} \frac{e^{-\delta a}}{\xi \sqrt{a}} \phi\left(\frac{z+\bar{z}-2 z_{D}-\mu a}{\xi \sqrt{a}}\right) d a .
\end{aligned}
$$

The two integrals can be computed as follows.

$$
\begin{aligned}
I_{1} & =\int_{0}^{\infty} \frac{e^{-\delta a}}{\xi \sqrt{2 \pi a}} \exp \left(-\frac{1}{2}\left(\frac{z-\bar{z}-\mu a}{\xi \sqrt{a}}\right)^{2}\right) d a \\
& =\frac{1}{\xi} \int_{0}^{\infty} \frac{1}{\sqrt{2 \pi a}} \exp \left(-\frac{1}{2 \xi^{2} a}[-2 z \mu a+2 \bar{z} \mu a]-\frac{1}{2 \xi^{2} a}\left[(z-\bar{z})^{2}+\left(2 \delta \xi^{2}+\mu^{2}\right) a^{2}\right]\right) d a \\
& =\frac{1}{\xi} \exp \left(\frac{(z-\bar{z}) \mu}{\xi^{2}}\right) \frac{1}{\sqrt{\frac{\mu^{2}+2 \xi^{2} \delta}{\xi^{2}}}} \exp \left(-\frac{|z-\bar{z}|}{\xi} \sqrt{\frac{\mu^{2}+2 \xi^{2} \delta}{\xi^{2}}}\right) \\
& =\frac{1}{\sqrt{\mu^{2}+2 \xi^{2} \delta}} \exp \left(\frac{1}{\xi^{2}}\left[(z-\bar{z}) \mu-|z-\bar{z}| \sqrt{\mu^{2}+2 \xi^{2} \delta}\right]\right)=\frac{\min \left\{e^{\nu_{*}(z-\bar{z})}, e^{-\nu(z-\bar{z})}\right\}}{\sqrt{\mu^{2}+2 \xi^{2} \delta}} .
\end{aligned}
$$


Let $z^{*}=z-z_{D}$ and $\bar{z}^{*}=\bar{z}-z_{D}$. Note that both are positive. Then

$$
\begin{aligned}
I_{2} & =\int_{0}^{\infty} \frac{e^{-\delta a}}{\xi \sqrt{2 \pi a}} \exp \left(-\frac{1}{2}\left(\frac{z^{*}+\bar{z}^{*}-\mu a}{\xi \sqrt{a}}\right)^{2}\right) d a \\
& =\frac{1}{\xi} \exp \left(\frac{\left(z^{*}+\bar{z}^{*}\right) \mu}{\xi^{2}}\right) \frac{1}{\sqrt{\frac{\mu^{2}+2 \xi^{2} \delta}{\xi^{2}}}} \exp \left(-\frac{\left|z^{*}+\bar{z}^{*}\right|}{\xi} \sqrt{\frac{\mu^{2}+2 \xi^{2} \delta}{\xi^{2}}}\right) \\
& =\frac{\exp \left(-\nu\left(z+\bar{z}-2 z_{D}\right)\right)}{\sqrt{\mu^{2}+2 \xi^{2} \delta}} .
\end{aligned}
$$

Using $\nu-\nu_{*}=-2 \mu / \xi^{2}$ from line 1 to line 2 and from line 3 to line 4 and using $\nu+\nu_{*}=$ $\left(2 / \xi^{2}\right) \sqrt{\mu^{2}+2 \delta \xi^{2}}$ from line 3 to line 4 , and combining these results we obtain

$$
\begin{aligned}
f(z) & =\frac{1}{\sqrt{\mu^{2}+2 \xi^{2} \delta}}\left[\min \left\{e^{\nu_{*}(z-\bar{z})}, e^{-\nu(z-\bar{z})}\right\}-\exp \left(-\frac{2 \mu\left(\bar{z}-z_{D}\right)}{\xi^{2}}-\nu\left(z+\bar{z}-2 z_{D}\right)\right)\right] \\
& =\frac{1}{\sqrt{\mu^{2}+2 \xi^{2} \delta}}\left[\min \left\{e^{\nu_{*}(z-\bar{z})}, e^{-\nu(z-\bar{z})}\right\}-e^{-\nu_{*}\left(\bar{z}-z_{D}\right)} e^{-\nu\left(z-z_{D}\right)}\right] \\
& =\frac{1}{\sqrt{\mu^{2}+2 \xi^{2} \delta}}\left[\frac{\min \left\{e^{\nu_{*}\left(z-z_{D}\right)} e^{\nu\left(z-z_{D}\right)}, e^{\nu_{*}\left(\bar{z}-z_{D}\right)} e^{\nu\left(\bar{z}-z_{D}\right)}\right\}-1}{e^{\nu_{*}\left(\bar{z}-z_{D}\right)} e^{\nu\left(z-z_{D}\right)}}\right] \\
& =-\frac{1}{\mu} \frac{\nu-\nu_{*}}{\nu+\nu_{*}}\left[\frac{\min \left\{e^{\left(\nu_{*}+\nu\right)\left(z-z_{D}\right)}, e^{\left(\nu_{*}+\nu\right)\left(\bar{z}-z_{D}\right)}\right\}-1}{e^{\nu_{*}\left(\bar{z}-z_{D}\right)} e^{\nu\left(z-z_{D}\right)}}\right] .
\end{aligned}
$$

\subsubsection{The Normalizing Constant}

In order to compute the probability densities $p(z)$ and $p_{1}(z)$ we need to integrate $f(z)$ and $f_{1}(z)$ over $z$, to find the corresponding normalizing constants.

$$
\begin{gathered}
\int_{z_{D}}^{\infty} f(z) d z=-\frac{1}{\mu e^{\nu_{*}\left(\bar{z}-z_{D}\right)}} \frac{\nu-\nu_{*}}{\nu+\nu_{*}} \int_{z_{D}}^{\infty}\left[\frac{\min \left\{e^{\left(\nu_{*}+\nu\right)\left(z-z_{D}\right)}, e^{\left(\nu_{*}+\nu\right)\left(\bar{z}-z_{D}\right)}\right\}-1}{e^{\nu\left(z-z_{D}\right)}}\right] d z \\
=-\frac{1}{\mu e^{\nu_{*}\left(\bar{z}-z_{D}\right)}} \frac{\nu-\nu_{*}}{\nu+\nu_{*}}\left\{e^{\left(\nu_{*}+\nu\right)\left(\bar{z}-z_{D}\right)} \int_{\bar{z}}^{\infty} e^{-\nu\left(z-z_{D}\right)} d z+\int_{z_{D}}^{\bar{z}} e^{\nu_{*}\left(z-z_{D}\right)} d z-\frac{1}{\nu}\right\} \\
=-\frac{1}{\mu e^{\nu_{*}\left(\bar{z}-z_{D}\right)}} \frac{\nu-\nu_{*}}{\nu+\nu_{*}}\left\{e^{\left(\nu_{*}+\nu\right)\left(\bar{z}-z_{D}\right)} \frac{e^{-\nu\left(\bar{z}-z_{D}\right)}}{\nu}+\left[\frac{e^{\nu_{*}\left(\bar{z}-z_{D}\right)}}{\nu_{*}}-\frac{1}{\nu_{*}}\right]-\frac{1}{\nu}\right\} \\
=-\frac{1}{\mu e^{\nu_{*}\left(\bar{z}-z_{D}\right)}} \frac{\nu-\nu_{*}}{\nu+\nu_{*}} \frac{\nu+\nu_{*}}{\nu_{*} \nu}\left\{e^{\nu_{*}\left(\bar{z}-z_{D}\right)}-1\right\}=\frac{1}{\mu-\nu_{*}}\left[e^{-\nu_{*}\left(\bar{z}-z_{D}\right)}-1\right] \\
=\frac{1-e^{-\nu_{*}\left(\bar{z}-z_{D}\right)}}{\delta},
\end{gathered}
$$

using $\nu-\nu_{*}=-2 \mu / \xi^{2}$, and $\nu \nu_{*}=2 \delta / \xi^{2}$. 


$$
\begin{gathered}
\int_{z_{L}}^{\infty} f_{1}(z) d z=-\frac{1}{\mu} \frac{\nu-\nu_{*}}{\nu+\nu_{*}} \int_{z_{L}}^{\infty}\left[\frac{\min \left\{e^{\left(\nu_{*}+\nu\right)\left(z-z_{L}\right)}, e^{\left(\nu_{*}+\nu\right)\left(z_{H}-z_{L}\right)}-1\right.}{e^{\nu_{*}\left(z_{H}-z_{L}\right)} e^{\nu\left(z-z_{L}\right)}}\right] d z \\
=-\frac{1}{\mu} \frac{\nu-\nu_{*}}{\nu+\nu_{*}} \frac{1}{e^{\nu_{*}\left(z_{H}-z_{L}\right)}}\left[\left[e^{\nu_{*}\left(z-z_{L}\right)}-e^{-\nu\left(z-z_{L}\right)}\right]_{z_{L}}^{z_{H}}+\left[e^{\left(\nu_{*}+\nu\right)\left(z_{H}-z_{L}\right)-\nu\left(z-z_{L}\right)}-e^{-\nu\left(z-z_{L}\right)}\right]_{z_{H}}^{\infty}\right] \\
=-\frac{1}{\mu} \frac{\nu-\nu_{*}}{\nu+\nu_{*}} \frac{1}{e^{\nu_{*}\left(z_{H}-z_{L}\right)}}\left[\frac{\left(\nu+\nu_{*}\right)\left[e^{\nu_{*}\left(z_{H}-z_{L}\right)}-1\right]}{\nu_{*} \nu}\right]=-\frac{1}{\mu} \frac{\nu-\nu_{*}}{\nu_{*} \nu}\left[1-e^{-\nu_{*}\left(z_{H}-z_{L}\right)}\right] \\
=\frac{1-e^{-\nu_{*}\left(z_{H}-z_{L}\right)}}{\delta} .
\end{gathered}
$$

The probability densities are thus

$$
p(z)=\frac{f(z)}{\frac{1}{\mu} \frac{\nu-\nu_{*}}{\nu_{*} \nu}\left[e^{-\nu_{*}\left(\bar{z}-z_{D}\right)}-1\right]}=\frac{\nu_{*} \nu}{\nu+\nu_{*}}\left[\frac{\min \left\{e^{\left(\nu_{*}+\nu\right)\left(z-z_{D}\right)}, e^{\left(\nu_{*}+\nu\right)\left(\bar{z}-z_{D}\right)}\right\}-1}{e^{\nu\left(z-z_{D}\right)}\left[e^{\nu_{*}\left(\bar{z}-z_{D}\right)}-1\right]}\right]
$$

and

$$
p_{1}(z)=\frac{f_{1}(z)}{-\frac{1}{\mu} \frac{\nu-\nu_{*}}{\nu_{*} \nu}\left[1-e^{-\nu_{*}\left(z_{H}-z_{L}\right)}\right]}=\left\{\begin{array}{cl}
\frac{\nu_{*} \nu}{\nu+\nu_{*}} \frac{e^{\left(\nu_{*}+\nu\right)\left(z-z_{L}\right)}-1}{e^{\nu\left(z-z_{L}\right)}\left[e^{\nu *\left(z_{H}-z_{L}\right)}-1\right]} & \text { if } z<z_{H} \\
\frac{\nu_{*} \nu}{\nu+\nu_{*}} \frac{e^{\left(\nu_{*}+\nu\right)\left(z_{H}-z_{L}\right)}-1}{e^{\nu\left(z-z_{L}\right)}\left[e^{\nu_{*}\left(z_{H}-z_{L}\right)}-1\right]} & \text { if } z>z_{H} .
\end{array}\right.
$$

\subsubsection{Export Sales and Size Probability Density (Proposition 1)}

The proof of Proposition 1 is the following. Export sales, $r_{1}(z)$, for a firm with efficiency $z$ are $[\sigma \tau /(\sigma-1)]^{1-\sigma} w X e^{(\sigma-1) z}$. Therefore,

$\operatorname{Pr}\left[r_{1}(z)<y\right]=\operatorname{Pr}\left[(\sigma \tau /(\sigma-1))^{1-\sigma} w X e^{(\sigma-1) z}<y\right]=\operatorname{Pr}\left[z<\frac{1}{\sigma-1} \ln \left(y(w X)^{-1}(\sigma \tau /(\sigma-1))^{\sigma-1}\right)\right]$

The probability density is

$$
p_{r 1}(y)=\frac{1}{(\sigma-1) y} p_{1}\left[\frac{1}{\sigma-1} \ln \left(y(w X)^{-1}(\sigma \tau /(\sigma-1))^{\sigma-1}\right)\right]
$$

where $p_{1}(z)$ is the probability density of $z$ for exporting firms. Using (40), when $z \geq z_{H}$, this expression can be rewritten as

$$
p_{r 1}(y)=\frac{1}{\sigma-1} \frac{\nu_{*} \nu}{\nu+\nu_{*}} \frac{e^{\left(\nu_{*}+\nu\right)\left(z_{H}-z_{L}\right)}-1}{e^{\nu_{*}\left(z_{H}-z_{L}\right)}-1} e^{\nu z_{L}}(w X)^{\nu \frac{1}{\sigma-1}}(\sigma \tau /(\sigma-1))^{-\nu} y^{-\frac{v}{\sigma-1}-1}
$$

showing that the density is proportional to $y^{-\frac{v}{\sigma-1}-1}$, therefore being Pareto distributed in the upper tail.

The proof for the size probability density $p_{l}(y)$ is analogous since variable employment, just 
like sales, is proportional to $\exp ((\sigma-1) z)$.

\subsubsection{Calibration Moments}

\section{Average Growth Rate of Variable Employment Conditional on Survival}

Note that variable labor demand is $l_{0}(z)=X[(\sigma-1) / \sigma]^{\sigma} \exp ((\sigma-1) z)$ for a nonexporter and $l_{1}(z)=\left(1+\tau^{-\sigma}\right) l_{0}(z)$ for an exporter. Itô's Lemma and the stochastic process for $z$, described in (2), imply that the stochastic process for variable labor employment is a geometric Brownian motion with drift $\left[(\sigma-1) \mu+0.5(\sigma-1)^{2} \xi^{2}\right] l_{0}(z)$ for nonexporters and with drift $\left[(\sigma-1) \mu+0.5(\sigma-1)^{2} \xi^{2}\right] l_{1}(z)$ for exporters. The average growth rate of variable employment (conditional on survival) is therefore $(\sigma-1) \mu+0.5(\sigma-1)^{2} \xi^{2}$.

\section{Average Death Rate of Small Firms}

Recall that equation (20) implies that the measure of nonexporters that switch to export is $-0.5(1-p) M \xi^{2} \partial p_{0}\left(z_{H}\right) / \partial z$. By analogy, the measure of nonexporters that shut down is $0.5(1-p) M \xi^{2} \partial p_{0}\left(z_{D}\right) / \partial z$ or, as a fraction of the measure of nonexporters,

$$
\frac{(1-p) M \frac{1}{2} \xi^{2} \frac{\partial p_{0}\left(z_{D}\right)}{\partial z}}{(1-p) M}=\frac{1}{2} \xi^{2} \frac{\partial p_{0}\left(z_{D}\right)}{\partial z}=\frac{1}{2} \xi^{2} \lim _{z \longrightarrow z_{D}^{+}} \frac{\partial p_{0}(z)}{\partial z}
$$

The derivative is determined as following. Since

$$
p(z)=(1-p) p_{0}(z)+p_{1}(z) p
$$

it is true that

$$
p_{0}(z)=\frac{p(z)-p_{1}(z) p}{1-p}=\frac{p(z)}{1-p} \text { for } z \in\left(z_{D}, z_{L}\right) .
$$

Then, using (39) for $z_{D}<z<\bar{z}<z_{H}$, we obtain

$$
\frac{\partial p(z)}{\partial z}=\frac{\nu_{*} \nu}{\nu+\nu_{*}} \frac{1}{e^{\nu_{*}\left(\bar{z}-z_{D}\right)}-1}\left[\nu_{*} e^{\nu_{*}\left(z-z_{D}\right)}+\nu e^{-\nu\left(z-z_{D}\right)}\right]
$$

and

$$
\lim _{z \longrightarrow z_{D}^{+}} \frac{\partial p(z)}{\partial z}=\frac{\nu_{*} \nu}{e^{\nu_{*}\left(\bar{z}-z_{D}\right)}-1} .
$$

Therefore

$$
\frac{\partial p_{0}\left(z_{D}\right)}{\partial z}=\frac{1}{1-p} \frac{\nu_{*} \nu}{e^{\nu_{*}\left(\bar{z}-z_{D}\right)}-1} .
$$

The fraction of nonexporters that shut down is

$$
m_{2}=\frac{1}{2} \xi^{2} \frac{1}{1-p} \frac{\nu_{*} \nu}{e^{\nu_{*}\left(\bar{z}-z_{D}\right)}-1} .
$$




\section{Percentage of Exporters Becoming Nonexporters}

Following similar steps as above, the measure of exporters that become nonexporters is $0.5 M p \xi^{2} \partial p_{1}\left(z_{L}\right) / \partial z$ or, as a fraction of the measure of exporters,

$$
\frac{M p \frac{1}{2} \xi^{2} \frac{\partial p_{1}\left(z_{L}\right)}{\partial z}}{p M}=\frac{1}{2} \xi^{2} \frac{\partial p_{1}\left(z_{L}\right)}{\partial z}=\frac{1}{2} \xi^{2} \lim _{z \longrightarrow z_{L}^{+}} \frac{\partial p_{1}(z)}{\partial z}
$$

The derivative is determined as following. Using equation for $z_{D}<z<z_{H}$,

$$
\frac{\partial p_{1}(z)}{\partial z}=\frac{\nu_{*} \nu}{\nu+\nu_{*}} \frac{1}{e^{\nu_{*}\left(z_{H}-z_{L}\right)}-1}\left[\nu_{*} e^{\nu_{*}\left(z-z_{L}\right)}+\nu e^{-\nu\left(z-z_{L}\right)}\right]
$$

and

$$
\lim _{z \longrightarrow z_{L}^{+}} \frac{\partial p_{1}(z)}{\partial z}=\frac{\nu_{*} \nu}{e^{\nu_{*}\left(z_{H}-z_{L}\right)}-1} .
$$

The fraction of exporters that become nonexporters is therefore

$$
m_{3}=\frac{1}{2} \xi^{2} \frac{\nu_{*} \nu}{e^{\nu_{*}\left(z_{H}-z_{L}\right)}-1} .
$$

\section{Percentage of Exporters}

This moment can be easily derived recalling that

$$
p=\frac{\int_{z_{H}}^{\infty} p(z) d z}{\int_{z_{H}}^{\infty} p_{1}(z) d z}
$$

and using equations (39) and (40). 